$n^{\circ} 2020-07$

\title{
Comparative Advantage and Moonlighting
}

\author{
Stéphane AURAY ${ }^{1}$ \\ David L. FULLER ${ }^{2}$ \\ Guillaume VANDENBROUCKE ${ }^{3}$
}

Les documents de travail ne reflètent pas la position du CREST et n'engagent que leurs auteurs. Working papers do not reflect the position of CREST but only the views of the authors.

${ }^{1}$ CREST-ENSAI and ULCO; e-mail: stephane.auray@ensai.fr.

${ }^{2}$ University of Wisconsin-Oshkosh; Email: fullerd@uwosh.edu.

${ }^{3}$ Research Division, Federal Reserve Bank of St. Louis, P.O. Box 442, St. Louis, MO 63166, USA; Email:guillaumevdb@gmail.com. 


\title{
Comparative Advantage and Moonlighting*
}

\author{
Stéphane Auray ${ }^{\dagger} \quad$ David L. Fuller ${ }^{\ddagger} \quad$ Guillaume Vandenbroucke ${ }^{\S}$
}

March 2020

\begin{abstract}
The prevalence of multiple jobholders in the U.S. data is trending down since the mid 1990s, and cross-sectional data reveal two seemingly contradictory patterns regarding multiple jobholders: (i) conditional on education the most productive workers are the least likely to hold multiple jobs; (ii) the most educated workers are the most likely to hold multiple jobs, even though they are the most productive. We develop an equilibrium model of the labor market to understand these facts. A dominating income effect explains both the negative correlation with productivity and the downward trend overtime, while a higher part-to-full time pay differential for skilled workers (a comparative advantage) explains the positive correlation with education. We provide empirical evidence of the comparative advantage using CPS data. We calibrate the model to 1994 and assess its ability to reproduce the 2017 data. There are three exogenous driving forces: productivity, number of children and the proportion of skilled workers. The model accounts for $64.1 \%$ of the moonlighting trend for college-educated workers, and $96.7 \%$ for high school-educated workers.
\end{abstract}

Keywords: Macroeconomics, labor supply, multiple jobholders, productivity, full-time job, part-time job, comparative advantage, income effect.

JEL classification: E1, J2, J22, J24, O4

${ }^{*}$ We thank participants at the Brown bag seminar of the Federal Reserve Bank of Saint Louis. S. Auray and D. Fuller thank CEPREMAP and the Chaire "Sécurisation des Parcours Professionnels at Sciences Po and GENES" for financial support. The views expressed in this article are ours and do not necessarily reflect the views of the Federal Reserve Bank of St. Louis or the Federal Reserve System.

${ }^{\dagger}$ CREST-Ensai and ULCO; Email: stephane.auray@ensai.fr.

${ }^{\ddagger}$ University of Wisconsin-Oshkosh; Email: fullerd@uwosh.edu

$\S$ Research Division, Federal Reserve Bank of St. Louis, P.O. Box 442, St. Louis, MO 63166, USA; Email: guillaumevdb@gmail.com. 


\section{InTRODUCTION}

Moonlighting, that is when a worker simultaneously holds more than one job, represents an important mechanism for workers to adjust their labor supply. More than $50 \%$ of males hold a second job at some point in their working lives (see Paxson and Sicherman (1996)). In the U.S., the proportion of multiple jobholders is around $5 \%$ at any point in time, of the same order of magnitude as the unemployment rate. Despite its importance, this margin of labor supply adjustment has not been studied as much as other extensive margins such as schooling, home production and retirement.

Documenting and explaining three facts regarding moonlighting is our goal. The first two are seemingly contradictory cross-sectional facts: (i) conditional on education, the most productive workers are the least likely to hold multiple jobs in any given year; and (ii) the most educated (and thus most productive) workers are the most likely to hold multiple jobs, in any given year. The third fact is: (iii) the declining trend in the prevalence of multiple jobholders for each education group. These facts are documented in Section 2. To the best of our knowledge, our paper is the first to examine the contradiction implied by comparing facts (i) and (iii) with fact (ii). ${ }^{1}$

In Section 3 we develop a static equilibrium model of the labor market with the following features. Workers are heterogeneous in their skills and preferences for leisure. There exists an exogenous skill distribution, where workers are either unskilled (i.e. high school diploma or less) or skilled (i.e. college-educated). Workers are also exogenously endowed with children, who impose a goods cost, with the number of children dependent on the worker's skill level. Workers have access to two types of jobs, full-time and part-time, and may choose one of five combinations: one full-time job, one part-time job, two full-time jobs, two parttime jobs and one full- and one part-time job. We focus exclusively on extensive margin adjustments, abstracting from the intensive margin. Thus, hours of work are fixed for each type of job. This assumption may be viewed similarly to an hours restriction, which Paxson and Sicherman (1996) and Lalé (2019) find to be an important reason why multiple jobs exist. The demand for labor is modeled via a production technology where the inputs of workers are imperfect substitutes across education (skill v. unskilled) and job type (part- v. full-time).

\footnotetext{
${ }^{1}$ Lalé (2019) also notes fact (ii).
} 
The model explains the data via two distinct mechanisms. First, fact (i)-the negative correlation between productivity and the prevalence of multiple jobholders, conditional on education - requires a dominating income effect: when productivity increases workers seek more leisure time. In the model this obtains by workers choosing one job instead of two. The dominating income effect also implies that the prevalence of multiple jobholding will decrease over time as productivity increases with economic growth. This is how our model explains fact (iii) - the declining trend in the prevalence of multiple jobholders.

Second, fact (ii) - the higher prevalence of multiple jobholders among college-educated - is explained by a comparative advantage effect. All else equal, the college wage premium and a dominating income effect imply less multiple jobholding among college-educated workers, opposite to fact (ii). Our analysis shows, however, that the model may capture fact(ii), if the part-time-to-full-time wage ratio is higher for college-educated workers than for high school-educated workers. That is, college-educated workers have a comparative advantage in part-time jobs. The logic behind this is as follows: consider two workers with identical preferences for leisure, but one is high school-educated and one is college-educated. Suppose that both work one full time job, and are considering taking a second, part-time job. The cost is identical for both of them, i.e., foregone leisure, but the benefit differs. The college premium implies that the marginal utility of consumption is higher for a high school-educated worker than for a college-educated worker. In order to induce the college-educated worker to take on the second job, but not the high school-educated worker, it must be that the increase in income resulting from the part-time job is larger for the college-educated than for the high school-educated.

We make the following observations about these two key mechanisms. First, evidence of the dominating income effect of wages on labor supply is provided by the long-run decline in hours per worker in the U.S. data. Evidence of this decline in the U.S. is provided in McGrattan and Rogerson (2004) and Vandenbroucke (2009); international evidence can be found in Restuccia and Vandenbroucke (2014). Pijoan-Mas (2006) and Heathcote et al. (2014) find evidence of dominating income effects in studies based on micro, cross-sectional data; Recently, Chang et al. (2019) emphasize the potential importance of a dominating income effect to understand the behavior of labor supply over the business cycle. While our analysis is not about the business cycle, this (non exhaustive) list should convince the reader that our emphasis on a dominating income effect is not at odds with the literature on labor supply. Second, we provide evidence of the comparative advantage of skilled workers 
in holding a second part-time job in Section 2. Specifically, using the Current Population Survey, we show that the change in hourly earnings between 1- and 2-job holders is increasing in education. ${ }^{2}$

Empirically, we proceed as follows. First we calibrate the model to cross-sectional U.S. data in 1994. We choose parameters to match the proportion of multiple jobholders by education, the proportion of workers in two part-time jobs, and the proportion of skilled and unskilled workers holding both a full- and a part-time job. We also target the college wage-premium and the average cost of raising children. Second, we compute an equilibrium of the model corresponding to 2017, assuming three differences between 1994 and 2017: (i) productivity increases exogenously in a way consistent with the observed change in the college premium and overall income growth; (ii) the proportion of skilled workers changes in a way consistent with growing college attainment; and (iii) the number of children for skilled and unskilled workers changes as in the U.S. data. We refer to this experiment as the "baseline."

It is important to note that not all parameterizations of the model imply a dominating income effect and/or a comparative advantage of college-educated workers. For some parameter values, the income and substitution effects may cancel out (e.g. logarithmic utility), or the substitution effect may dominate the income effect. In such cases our model could not account for facts (i) and (iii). In Section 4.1 we explain that the parameters governing the strength of the comparative advantage of skilled workers also governs the relative strength of the income and substitution effects. Thus, our calibration strategy of matching the prevalence of multiple jobholders across education groups, which disciplines the comparative advantage, also imposes discipline on the relative strength of the income and substitution effects. Our finding is a dominating income effect, hence the ability of our model to account for facts (i)-(iii).

In the baseline experiment the calibrated model replicates the ordering of the prevalence of multiple jobholders by skill group well, in both the initial and final equilibrium. Over time the model accounts for $64.1 \%$ of the decline in the proportion of multiple jobholders among skilled workers, and $96.7 \%$ for unskilled workers.

We also conduct counterfactual experiments to investigate the contribution of each variable.

\footnotetext{
${ }^{2}$ Paxson and Sicherman (1996) discusses a similar finding, noting several cases where the ratio of the second job wage to the main job appears to be increasing in education. For example, the ratio is higher for university and college teachers compared to primary and secondary teachers. Paxson and Sicherman (1996) do not fully explore this pattern based on education, however.
} 
The results show that productivity alone has a strong effect on the moonlighting trend of skilled workers ( $72.7 \%$ of the actual decline) but a small effect for unskilled workers $(7 \%$ of the actual decline). This is because, in order to replicate the increasing skill premium between 1994 and 2017, the productivity of skilled workers must increase while that of unskilled workers decreases. In the absence of rising educational attainment this results in almost-stagnating wages for unskilled workers and, hence, little changes in the proportion of unskilled multiple jobholders over time. Rising educational attainment, which occurs in the baseline experiment, mitigates these effects. This is because rising educational attainment, on its own, has large but opposite effects on the proportion of multiple jobholders: when the proportion of skilled workers increases skilled wages decrease (all else equal), and unskilled wages increase. Together, productivity and educational attainment imply moonlighting trends similar the trends implied by the baseline experiment. The number of children, which increased for skilled workers and decreased for the unskilled also has a significant, albeit smaller effect. For unskilled workers, the decline in the number of children alone accounts for $14.4 \%$ of the decline of the proportion of multiple jobholders.

Our paper contributes to the macroeconomic literature on long-run trends and/or country differences in labor markets. ${ }^{3}$ A common theme in this literature is the emphasis on some form of extensive margin of labor supply either between home and the market (e.g. Greenwood et al., 2005; Ngai and Pissarides, 2008; Kopecky, 2011; Aguiar et al., 2017); or between schooling, leisure and the market (e.g. Restuccia and Vandenbroucke, 2014); or between sectors (e.g. Rogerson, 2008). We complement this literature by emphasizing another margin of labor supply, i.e., the number of jobs, and by focusing simultaneously on the the long-run and the cross-sectional behavior along this margin.

The existing literature on multiple jobholders focuses on understanding why multiple jobholders exist. An early model can be found in Shishko and Rostker (1976). Kimmel and Smith Conway (2001) documents who moonlights and why. Paxson and Sicherman (1996) hypothesize that multiple jobholding arises from hours restrictions that workers' face, and they focus specifically on the trade-off between job mobility and multiple jobholding. Empirically, they find evidence that hours restrictions indeed drive the phenomenon, and supports a mobility-multiple jobs trade-off. They formulate a dynamic model where workers desiring more hours can either change jobs or add a second job. As we focus on the extensive margin

\footnotetext{
${ }^{3}$ Hirsch et al. (2016) concludes that the rate of multiple jobholders is mostly acyclical. Thus, our paper does not contribute to the literature on the business cycle behavior of hours worked.
} 
only, our model may be interpreted as imposing a similar hours restriction.

Lalé (2019) also focuses on the micro-determinants of multiple jobholding, and represents an important contribution to the theory of why workers choose multiple jobs instead of increasing hours or changing jobs entirely. He develops a search-theoretic model of the labor market where hours and wages in the primary and secondary job are determined endogenously. While Lalé (2019) focuses primarily on understanding why workers choose multiple jobs instead of more hours, he does use the model to examine the declining trend in the prevalence of multiple jobholders that we also study. He finds this trend results from decreased flows into multiple jobholding (as opposed to shorter durations of the second job). His model attributes most of the declining trend in the prevalence of multiple jobholders to an increase in the cost of working a second job.

Our paper's contribution to this literature is many fold. First, we emphasize an apparent contradiction that has not been pointed out in the existing literature: on the one hand there is a negative correlation between productivity and the prevalence of multiple jobholders, conditional on education, both in time series and in cross-sectional data; on the other hand the prevalence of multiple jobholders is increasing with education. Our paper proposes a resolution of this apparent contradiction. Second, we present a systematic empirical analysis of the effects of education, wages, and children on multiple jobholding, and draw connections between these cross-sectional features and long-run trends.

\section{DATA}

In this section we describe the data and establish several important empirical facts regarding multiple jobholders. The Current Population Survey (CPS) is our primary data set. Specifically we use the Outgoing Rotations Group (ORG). This particular extract of the CPS follows individuals for four months after they enter the survey, they are ignored for eight months, and then interviewed for four more months. The primary advantage of this data set is the availability of earnings information, which is gathered during months four and eight for each individual. In these months individuals are asked questions regarding hours worked and earnings, both overall and in their "usual" job. Multiple jobholders are defined as those workers who had two or more jobs in the reference week of the CPS survey. Data on multiple jobholders are available starting in 1994. While the definition of multiple jobholders includes 
two or more jobs, in our sample less than 1 percent of all multiple jobholders had more than two jobs; therefore, hereafter we take multiple jobs to refer to an individual working two jobs. ${ }^{4}$

\subsection{Overview}

Figure 1 plots the percentage of employed individuals working more than one job over time by education, comparing workers with a high school diploma or less to workers with at least some college education. First, note that regardless of education, the percentage of multiple jobholders has steadily declined since 1998. Second, multiple jobholding is positively associated with education level, with the Some-college group having a higher percentage of workers in multiple jobs. ${ }^{5}$ This pattern holds regardless of how coarsely we define the education groups. For example, consider the maximum number of education groups available in the data. In 2015, among workers that did not graduate from high school, 2.1 percent had more than one job. For workers with a high school degree, 3.4 percent were multiple jobholders. For high school graduates that received up to 4 years of college education, the same percentage was 5.1. Finally, 6.3 percent of workers with an advanced college degree had more than one job. This relative ranking is robust across all years in the data.

These two facts paint contrasting pictures. To see this, consider Figure 2 which plots the percentage of multiple jobholders (left axis) and the average real hourly wage (in 2017 \$'s on the right axis). There is a negative correlation between multiple jobholding and productivity; furthermore, we show in Section 2.2 below that there is also a negative correlation between multiple jobholding and wages in cross-sectional data, conditional on education. If higher productivity reduces the likelihood of working multiple jobs, then high productivity workers should be less likely to work multiple jobs. Since education is positively correlated with productivity, there should then be a negative correlation between the level of education and the percentage of multiple jobholders. It is not the case, hence the apparent contradiction.

Figure 3 shows hours worked by type of worker and education. The average single jobholder works slightly less than 40 hours per week, while the average multiple jobholder works around 10 additional hours each week. Note that these figures do not trend over time. We use these

\footnotetext{
${ }^{4}$ See Appendix A, Figure A.1.

${ }^{5}$ Figure A.2 of Appendix A shows that the downward trend in the proportion of multiple jobholders is true for both men and women, albeit it is more pronounced for men.
} 


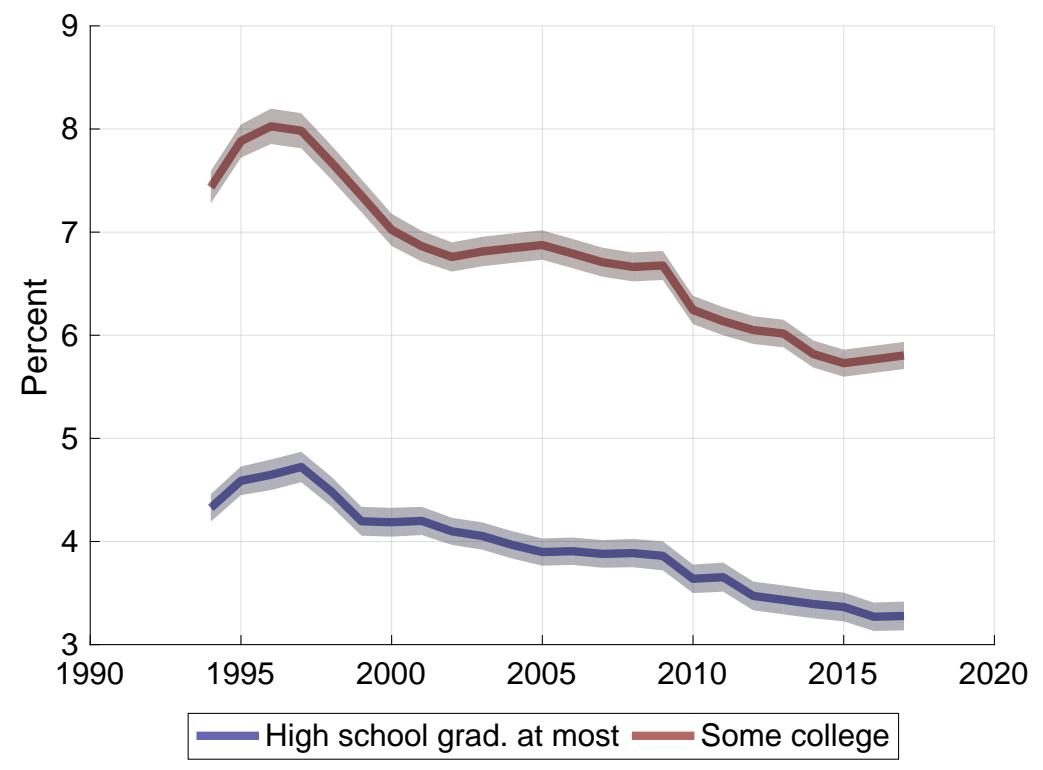

Figure 1: Proportion of employees with two jobs, by education

Note: The shaded areas indicate $95 \%$ confidence intervals.

Source: Current Population Survey. 


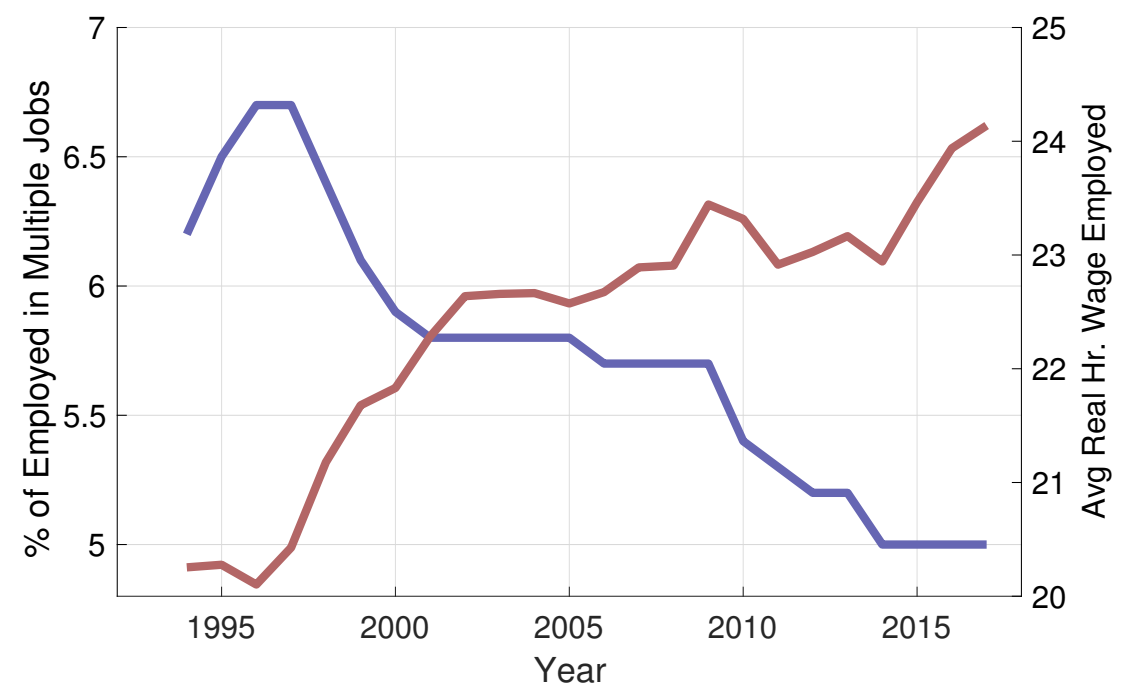

$\%$ of mult. job holders $=$ Avg. hourly wage

Figure 2: Proportion of employees with multiple jobs (LHS) and Avg. real wages (RHS) Source: Current Population Survey. 
observations to justify several features of our model in Section 3. First, we do not model the intensive margin of labor supply. That is, we do not allow workers in our model to adjust their hours by any other means than by adjusting the number of jobs they work. In this, we appeal to the existing literature that finds restrictions limiting a worker's ability to adjust hours in a given job are a key reason for moonlighting (see Paxson and Sicherman (1996) and Lalé (2019)). Second, we assume that there are two types of jobs: a "full-time" job requiring 40 hours of work, and a "part-time" job requiring 10 hours of work. This assumption follows Figure 3, which indicates that multiple jobholders do not work twice as many hours as single jobholders. We adopt these numbers so that the average multiple jobholders in our model works the same additional hours as the average multiple jobholders in the U.S. data. ${ }^{6}$

Multiple jobholders can either work two part-time jobs (PP), two full-time jobs (FF) or one part- and one full-time job (FP). The distribution of multiple jobholders across these categories is noticeably stable over time. For instance, 50 percent of multiple jobholders are "FP-workers" in 1994, compared to 49.9 percent in 2017. Similarly, 33 percent of multiple jobholders are "PP-workers" in 1994, the same percent as in 2017. Figure 4 shows the proportion workers in these categories by education. Note that FP-workers are the most prevalent, and college educated workers have the highest percent within each arrangement. We allow workers to choose among these different work arrangements in our model (in addition to the possibility of working one full-time job or one part-time job). The data presented in Figure 4 is used to calibrate the model.

Figure 5 shows the number of children under 18 for employed individuals between the age of 20 and 55. Section 2.2 below presents evidence that the number of children is an important correlate of multiple jobholding; therefore, we discuss here the general trend in the number of children for our two education groups. Figure 5 reveals a generally decreasing trend in the number of children for the high school group, and a generally increasing trend for the college group. ${ }^{7}$ In the model of Section 3 we endow workers with an exogenous number of children, and, in the quantitative analysis of Section 4, we let this number change in line with the data presented in Figure 5.

\footnotetext{
${ }^{6}$ Our choice of 10 masks some heterogeneity since a number of multiple jobholders work flexible hours on their main and/or second job. Kimmel and Smith Conway (2001) find that most multiple jobholders work fulltime on their primary jobs and 15 to 20 hours per week on their second jobs.

${ }^{7}$ This general pattern is consistent with Bar et al. (2018) who find an increase in fertility among higher income families over the past 25 years.
} 


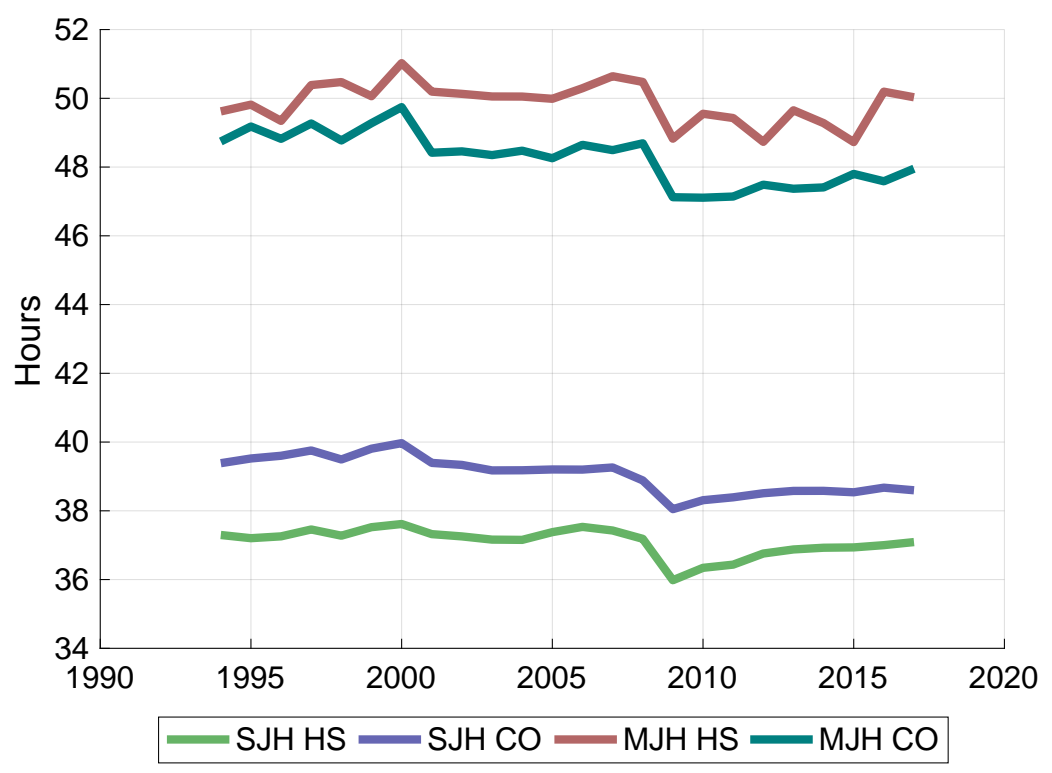

Figure 3: Weekly hours worked

Note: "SJH" means single jobholder and "MJH" means multiple jobholder. "HS" means at most high school graduate and "CO" means some college education.

Source: Current Population Survey. 


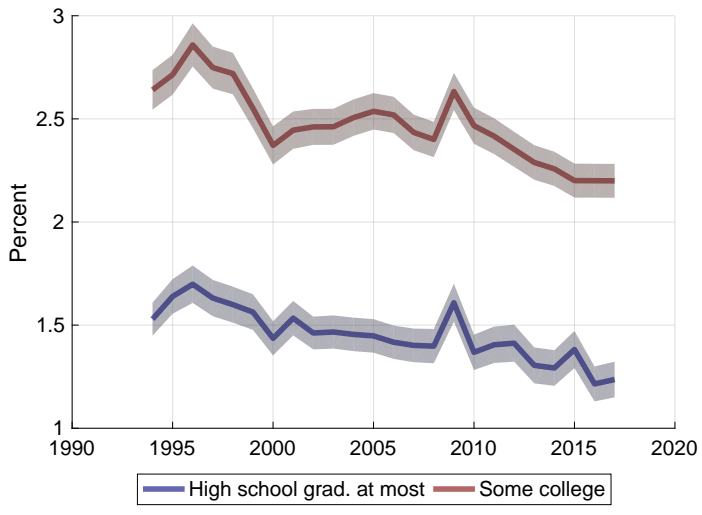

A - PP workers

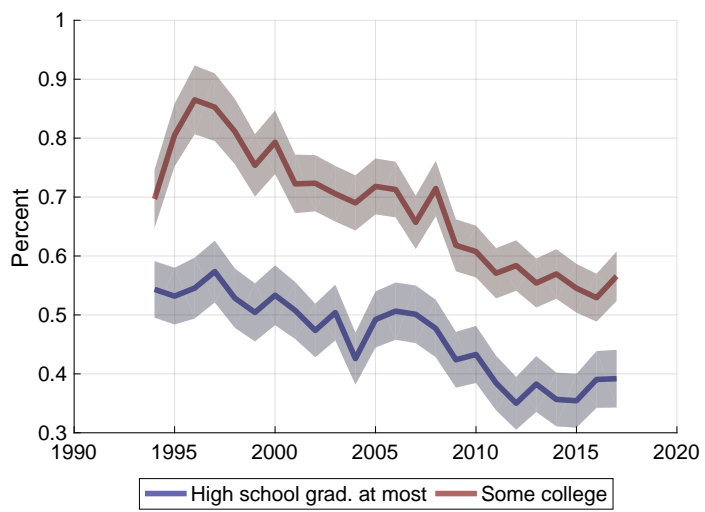

C - FF workers

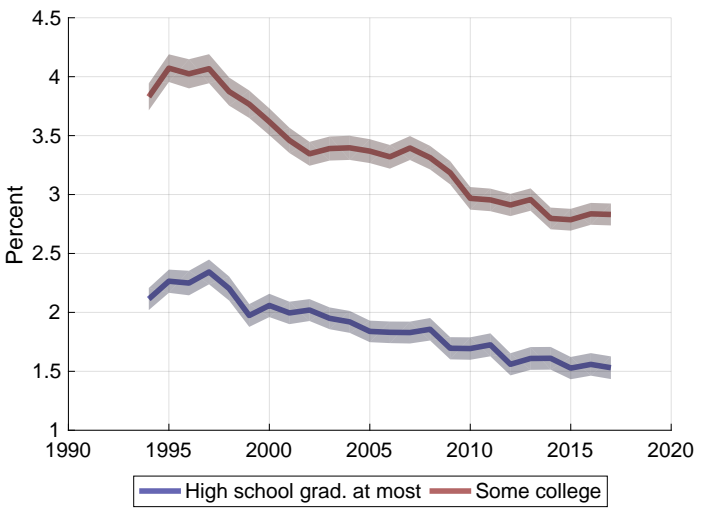

$\mathrm{B}$ - FP workers

Figure 4: Proportion of multiple jobholders by type of jobs and education

Note: The shaded areas indicate $95 \%$ confidence intervals.

Source: Current Population Survey. 


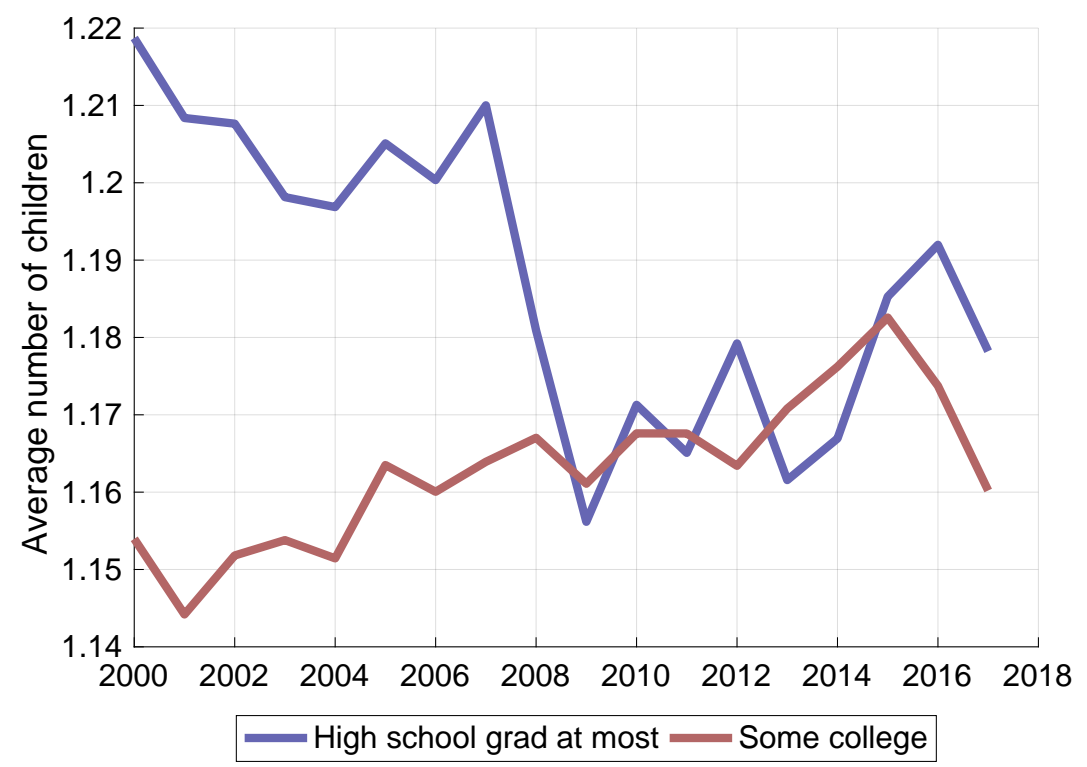

Figure 5: Average number of children under 18 by education Source: Current Population Survey. 


\subsection{Correlations}

In this section we analyze correlates of multiple jobholding using a probit model with a (0/1) indicator variable for multiple jobholding as the dependent variable. Table 1 presents the results. The coefficient estimates are presented as odds ratios, so a coefficient less (greater) than 1 indicates a characteristic that reduces (increases) the likelihood of working multiple jobs. The models are estimated separately for males and females, under several alternative specifications. All specifications include both State and Year fixed effects.

The specifications in Models 1 and 2 differ in the treatment of children. From 2000-2017, the CPS data contain the ages of the adult respondents' children. Specifically the data contain the number of children under the age of 18 in the household. "Model 1" is a specification using the number of children under the age of 18 as an explanatory variable; "Model 1F" is restricted to females, "Model $1 \mathrm{M}$ " is restricted to males (the same notation holds for Models 2 and 3), and "Model 1A" uses all observations but includes an indicator for Female (=1 if female). "Model 2" includes indicator variables for having children of a certain age, e.g. children ages 0-2, 3-5, etc. For these indicator variables the reference group is no children under the age of 18. "Model 3" is the same as Model 2, except that we also add indicator variables for Occupation. We only have a consistent set of Occupation definitions starting in 2003, so we lose some observations in this model

Several interesting patterns emerge in Table 1. First, across all specifications education has a positive effect on multiple jobholding (Less than high school is the reference group for the education indicators). To gauge the economic magnitude of the effect of education Figure 6 plots the probability of multiple jobholding predicted by Model $1 \mathrm{~A}$ as a function of the level of education, all other variables held constant at their sample mean. Figure 6 suggests that the effect of education is both statistically and economically significant: the probability of multiple jobholding being multiplied by more than three over the education spectrum.

Second, the costs associated with children represents a possible reason why workers may decide to work multiple jobs. From models $1 \mathrm{~F}$ and $1 \mathrm{M}$, the presence of children reduces the likelihood of multiple jobholding for women, and increases it for men. This may be interpreted as follows. Children impose both a time and a goods cost on households, although the time cost is borne primarily by the mother. The presence of a child thus induces the father to accept a second job to help with the goods cost, while it deters the mother in order to help with the time cost. This is confirmed by Models 2 and 3 where it appears that, as 
Table 1: Probit Model Multiple Jobholding Dependent Variable

\begin{tabular}{|c|c|c|c|c|c|c|c|}
\hline Variables & $\begin{array}{c}(1) \\
\text { Model } 1 \mathrm{~F}\end{array}$ & $\begin{array}{c}(2) \\
\text { Model } 1 \mathrm{M}\end{array}$ & $\begin{array}{c}(3) \\
\text { Model 1A }\end{array}$ & $\begin{array}{c}(4) \\
\text { Model } 2 \mathrm{~F}\end{array}$ & $\begin{array}{c}(5) \\
\text { Model } 2 \mathrm{M}\end{array}$ & $\begin{array}{c}(6) \\
\text { Model } 3 \mathrm{~F}\end{array}$ & $\begin{array}{c}(7) \\
\text { Model } 3 \mathrm{M}\end{array}$ \\
\hline \multicolumn{8}{|c|}{ Education (Less than HS reference group) } \\
\hline HS & $\begin{array}{c}1.179^{* * *} \\
(0.0178)\end{array}$ & $\begin{array}{c}1.259^{* * *} \\
(0.0175)\end{array}$ & $\begin{array}{c}1.217^{* * *} \\
(0.0131)\end{array}$ & $\begin{array}{c}1.182^{* * *} \\
(0.0177)\end{array}$ & $\begin{array}{c}1.258^{* * *} \\
(0.0174)\end{array}$ & $\begin{array}{c}1.185^{* * *} \\
(0.0187)\end{array}$ & $\begin{array}{c}1.260 * * * \\
(0.0174)\end{array}$ \\
\hline Some college & $\begin{array}{c}1.407^{* * *} \\
(0.0217)\end{array}$ & $\begin{array}{c}1.499 * * * \\
(0.0236)\end{array}$ & $\begin{array}{c}1.453^{* * *} * \\
(0.0171)\end{array}$ & $\begin{array}{l}1.411^{* * *} \\
(0.0217)\end{array}$ & $\begin{array}{c}1.498^{* * *} * \\
(0.0236)\end{array}$ & $\begin{array}{c}1.407^{* * *} \\
(0.0235)\end{array}$ & $\begin{array}{c}1.464^{* * *} * \\
(0.0203)\end{array}$ \\
\hline College & $\begin{array}{c}1.456^{* * *} \\
(0.0272)\end{array}$ & $\begin{array}{c}1.544^{* * *} \\
(0.0277)\end{array}$ & $\begin{array}{c}1.501^{* * *} * \\
(0.0210)\end{array}$ & $\begin{array}{l}1.465 * * * \\
(0.0273)\end{array}$ & $\begin{array}{c}1.543^{* * *} \\
(0.0277)\end{array}$ & $\begin{array}{c}1.432^{* * *} \\
(0.0303)\end{array}$ & $\begin{array}{c}1.469^{* * *} \\
(0.0253)\end{array}$ \\
\hline Advanced & $\begin{array}{c}1.646^{* * *} \\
(0.0304)\end{array}$ & $\begin{array}{c}1.755^{* * *} \\
(0.0358)\end{array}$ & $\begin{array}{c}1.703^{* * *} \\
(0.0280)\end{array}$ & $\begin{array}{c}1.668^{* * *} \\
(0.0308)\end{array}$ & $\begin{array}{c}1.755^{* * *} \\
(0.0358)\end{array}$ & $\begin{array}{c}1.598^{* * *} \\
(0.0311)\end{array}$ & $\begin{array}{c}1.609^{* * *} \\
(0.0272)\end{array}$ \\
\hline Number of children & $\begin{array}{c}0.976^{* * *} \\
(0.00227)\end{array}$ & $\begin{array}{c}1.026^{* * *} \\
(0.00294)\end{array}$ & $\begin{array}{c}1.004^{* *} \\
(0.00220)\end{array}$ & & & & \\
\hline \multicolumn{8}{|c|}{ Age of Children (No children under 18 reference group) } \\
\hline Child $0-2$ & & & & $\begin{array}{l}0.820^{* * *} \\
(0.00594)\end{array}$ & $\begin{array}{l}1.028^{* * *} \\
(0.00751)\end{array}$ & $\begin{array}{c}0.808 * * * \\
(0.00653)\end{array}$ & $\begin{array}{l}1.023^{* * *} \\
(0.00846)\end{array}$ \\
\hline Child 3-5 & & & & $\begin{array}{c}0.927 * * * \\
(0.00642)\end{array}$ & $\begin{array}{l}1.038^{* * *} \\
(0.00861)\end{array}$ & $\begin{array}{c}0.923^{* * *} \\
(0.00690)\end{array}$ & $\begin{array}{l}1.036^{* * *} \\
(0.00850)\end{array}$ \\
\hline Child 6-13 & & & & $\begin{array}{l}0.948^{* * *} \\
(0.00625)\end{array}$ & $\begin{array}{l}1.020^{* * *} \\
(0.00522)\end{array}$ & $\begin{array}{l}0.943^{* * *} \\
(0.00604)\end{array}$ & $\begin{array}{c}1.015^{* *} \\
(0.00594)\end{array}$ \\
\hline Child 14-17 & & & & $\begin{array}{l}1.068^{* * *} \\
(0.00619)\end{array}$ & $\begin{array}{l}1.062^{* * *} \\
(0.00831)\end{array}$ & $\begin{array}{l}1.060^{* * *} \\
(0.00574)\end{array}$ & $\begin{array}{l}1.066^{* * *} \\
(0.00882)\end{array}$ \\
\hline Female $(\mathrm{Y} / \mathrm{N})$ & & & $\begin{array}{l}0.885^{* * *} \\
(0.00625)\end{array}$ & & & & \\
\hline Real wage, 2017 \$'s & $\begin{array}{c}0.999^{* * *} \\
(0.000339)\end{array}$ & $\begin{array}{c}0.997^{* * *} \\
(0.000293)\end{array}$ & $\begin{array}{c}0.998^{* * *} \\
(0.000286)\end{array}$ & $\begin{array}{c}0.999^{* * *} \\
(0.000337)\end{array}$ & $\begin{array}{c}0.997^{* * *} \\
(0.000293)\end{array}$ & $\begin{array}{c}0.999^{* * *} \\
(0.000337)\end{array}$ & $\begin{array}{c}0.998^{* * *} \\
(0.000265)\end{array}$ \\
\hline Married & $\begin{array}{l}0.829 * * * \\
(0.00544)\end{array}$ & $\begin{array}{c}1.038^{* * *} \\
(0.0129)\end{array}$ & $\begin{array}{l}0.894^{* * *} \\
(0.00581)\end{array}$ & $\begin{array}{l}0.835^{* * *} \\
(0.00558)\end{array}$ & $\begin{array}{c}1.040^{* * *} \\
(0.0130)\end{array}$ & $\begin{array}{l}0.834^{* * *} \\
(0.00640)\end{array}$ & $\begin{array}{c}1.052^{* * *} \\
(0.0147)\end{array}$ \\
\hline Constant & $\begin{array}{l}0.165^{* * *} \\
(0.00374)\end{array}$ & $\begin{array}{l}0.151^{* * *} \\
(0.00358)\end{array}$ & $\begin{array}{l}0.176^{* * *} \\
(0.00325)\end{array}$ & $\begin{array}{l}0.162^{* * *} \\
(0.00369)\end{array}$ & $\begin{array}{l}0.151^{* * *} \\
(0.00357)\end{array}$ & $\begin{array}{l}0.148^{* * *} \\
(0.00399)\end{array}$ & $\begin{array}{l}0.140^{* * *} \\
(0.00314)\end{array}$ \\
\hline Observations & $1,018,409$ & 978,118 & $1,996,527$ & $1,018,409$ & 978,118 & 846,628 & 811,143 \\
\hline State FE & YES & YES & YES & YES & YES & YES & YES \\
\hline Year FE & YES & YES & YES & YES & YES & YES & YES \\
\hline Occupation FE & & & & & & YES & YES \\
\hline
\end{tabular}




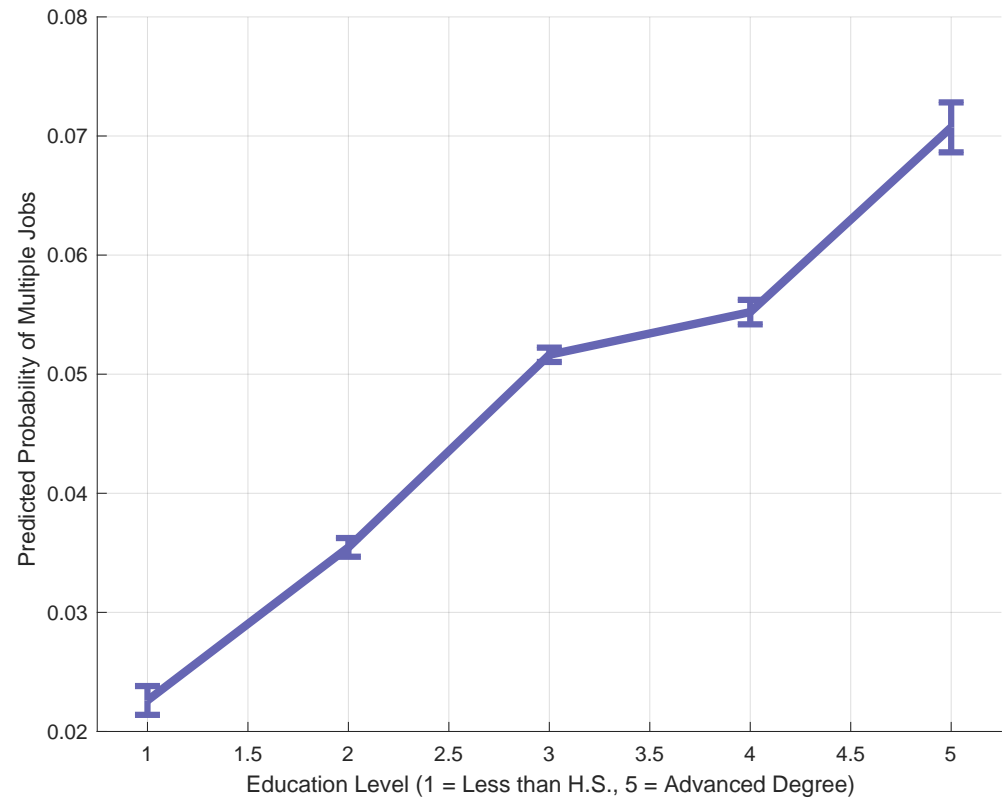

Figure 6: Predicted probabilities as a function of education level

Note: Calculated at the mean of all covariates. 


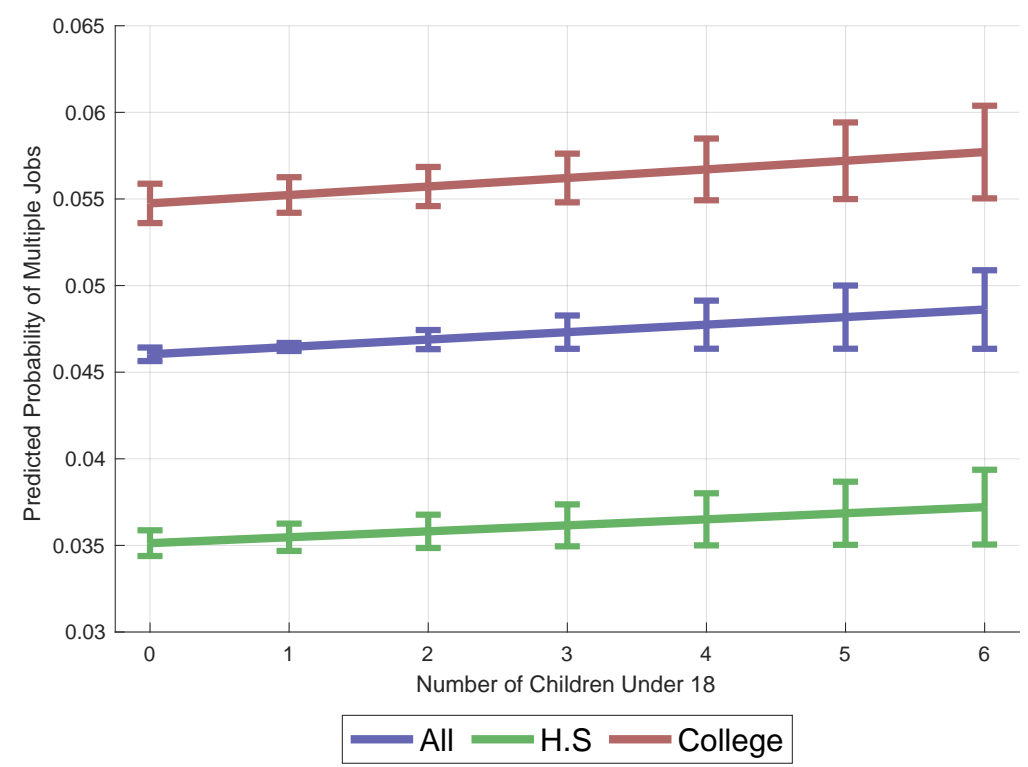

Figure 7: Predicted probabilities as a function of number of children

Note: Calculated at the mean of all covariates.

children become older, the mother is less likely to spend time at home and more likely to take on a second job. The importance of the second job may also increase as the children becomes older because of the need to finance their education. In the model of Section 3 we only model the good cost of a child, and abstract from the time cost. We do this to simplify the analysis given the fact that the time cost is age-related, and thus would require a model that distinguishes between gender and age.

Figure 7 plots the probability of multiple jobholding predicted by model $1 \mathrm{~A}$ as a function of the number of children, all other variables held constant at their sample mean. All else equal, more children raises the likelihood of multiple jobholding. From Figure 7, this effect appears relatively small. This is due to the fact that in model $1 \mathrm{~A}$ the worker is of the "average gender," unlike in model $1 \mathrm{~F}$ or $1 \mathrm{M}$ where gender is fixed. As mentioned above, the coefficients for models $1 \mathrm{~F}$ and $1 \mathrm{M}$ show that the effect of children is positive for men and negative for women. The small effect of children in model $1 \mathrm{~A}$ is the combination of these two opposing forces. Since, on the one hand, our theoretical model of Section 3 does not distinguish between gender, the worker in the model may be viewed as corresponding 


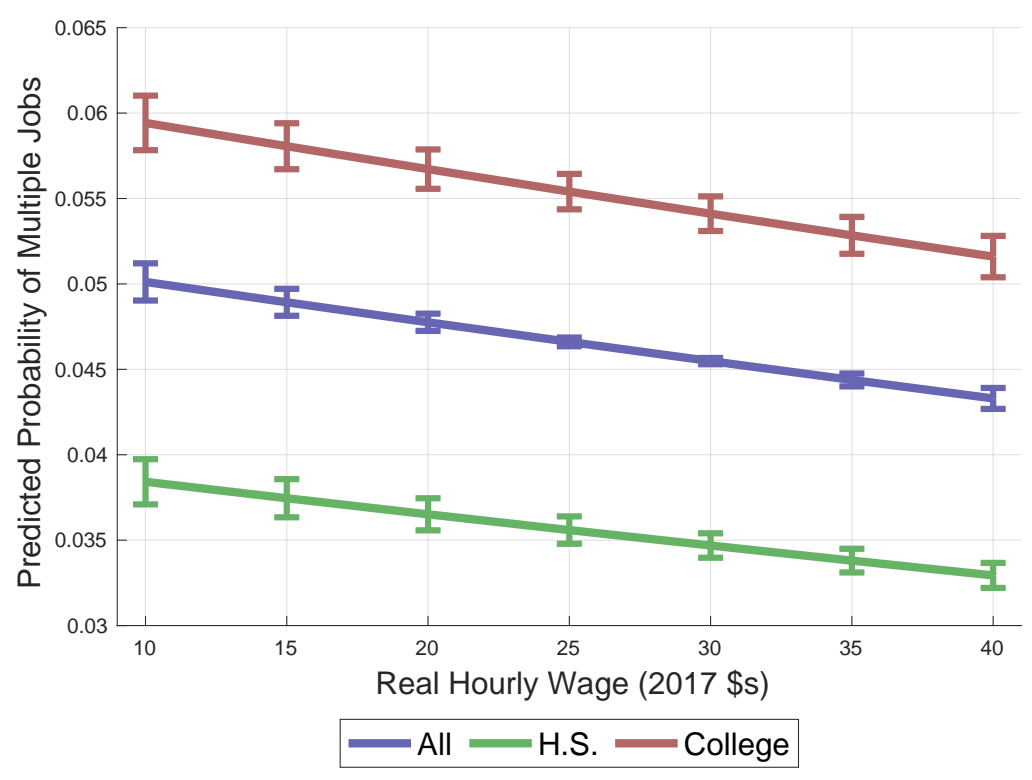

Figure 8: Predicted probabilities as a function of the real wage

Note: Calculated at the mean of all covariates. Bars indicate $95 \%$ confidence intervals.

to the worker represented in Probit model 1A. On the other hand, the theoretical model features only a goods cost, which as we have explained above, is borne by men. From this perspective the worker in the theoretical model would be closer to the worker represented in Probit model 1M. In both cases the effect of children is positive, albeit the effect is stronger in Probit model 1M.

Third, in all models the real wage has a negative effect on multiple jobholding. ${ }^{8}$ Thus, conditional on characteristics such as education and family size/composition, higher real wages reduce the incidence of multiple jobholding. We interpret this result as indicating that more productive workers are less likely to be multiple jobholders. Although the coefficients are close to one, the negative effect of real wages is statistically significant. Figure 8 shows the predicted probability of multiple jobholding as a function of the real wage. This confirms the significant negative relationship across education groups and holding all other characteristics fixed.

\footnotetext{
${ }^{8}$ Real wages are hourly earnings on the usual job, including overtime, tips, and commissions. The nominal wages are converted to 2017 \$'s using the CPI-U-RS (see www.bls.gov)
} 
The statistical models reported in Table 1 also include other demographic characteristics, including marital status, age and race. In all specifications, marriage has a negative effect on female multiple jobholding, and a positive effect for males. For both males and females, age has a non-monotonic effect. In all but model $3 \mathrm{~F}$, age has a positive effect on multiple jobholding with the peak effect for the 40-49 age group. Black, Hispanic, and Other races are generally less likely to be multiple jobholders relative to White, with the effects slightly stronger for females relative to males. Table 7 in Appendix A reports the full set of parameters in our estimations.

\subsection{Evidence of comparative advantage}

As we discussed in Section 1, the model developed below implies that the most educated workers must have a comparative advantage in taking a second job in order to explain the higher prevalence of multiple jobholders among them. Specifically, the gain from a second job must be increasing in education. In this section, we offer evidence of the presence of such a comparative advantage in the data. To do so, we estimate two separate earnings equations for single and multiple jobholders. For each equation we use Heckman's (1976) sample correction to account for the fact that selection into the group of multiple or single jobholders is not random. We then use the earnings equations to compute the average hourly earnings of workers with one or multiple jobs, by education.

The models estimated are

$$
\begin{aligned}
\ln \left(e_{j}\right) & =\theta_{j} X+\epsilon \\
\operatorname{Pr}(\text { number of jobs }=j) & =\operatorname{Pr}\left(\gamma_{j} \tilde{X}+\nu>0\right)
\end{aligned}
$$

where, for each model, $\epsilon$ and $\nu$ are jointly normally distributed random variables with mean zero. The variable $e_{j}$ indicates total hourly earnings on all jobs for workers with one job $(j=1)$ or workers with multiple jobs $(j=m)$. The variable $X$ contains the worker's age (and the square of age), indicator functions for education, sex and race as well as state, year and occupation fixed effects. The selection equation follows the models we estimated

in Table 1 . Thus $\tilde{X}$ contains $X$ as well as the number of children and the worker's marital status.

We estimate the two models $(j=1, m)$ separately using Heckman's two-step estimator. 


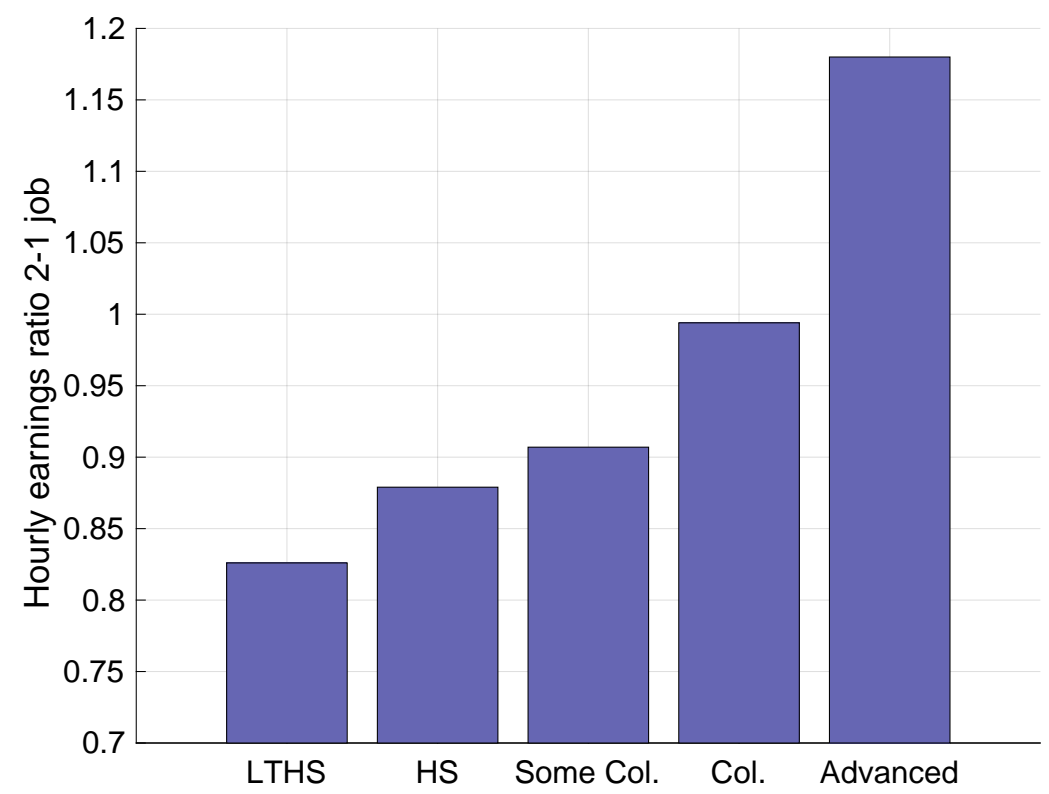

Figure 9: Hourly earnings difference between 1- and 2-jobholders Source: Current Population Survey and authors' calculations 
When estimating the model for single (multiple) jobholders, that is $j=1(j=m)$, we consider observations for multiple (single) jobholders to be missing. Figure 9 reports the ratio of total hourly earnings (implied by our estimated models) between workers with multiple jobs and workers with one job, by education.

An earnings ratio increasing with education represents the main lesson from Figure 9. This indicates that workers with the highest education have the most to gain from working multiple jobs. Importantly, this provides evidence of the comparative advantage mechanism that our model implies is necessary to explain the higher prevalence of multiple jobholding among college-educated workers.

It is important to note that our calculation does not directly compare the earnings on a worker's first and second job. Instead, it compares total hourly earnings between single jobholders and multiple jobholders. Figure 9 reveals that total hourly earnings of multiple jobholders tend to be lower than that of single jobholders. Since a large fraction of multiple jobholders work one full- and one part-time job, this suggests that part-time wages are in general lower than full-time wages. Note the exception for college-educated workers, though. For these workers the second job does not reduce (college) and may even increase the hourly earnings (advanced).

Paxson and Sicherman (1996, Table 5) report the means and medians of the ratio of the second to main job wage rate for a variety of occupational groups. The evidence is, in the authors words, "sketchy" as to the magnitude of this ratio. For some groups the ratio is below one, indicating that the wage on the second job is lower than on the main job (e.g. the median ratio is 0.863 for "Operatives). For some groups the ratio is above one, indicating that the wage on the second job is higher than on the main job (e.g. the median ratio is 1.293 for "college teachers). The overall median ratio is 1.050 .

The Paxson and Sicherman (1996) evidence is consistent with our results along two dimensions. First, the lack of a clear-cut ordering of main and second job wage rates is consistent with the heights of bars in Figure 9: for some workers the second job reduces their hourly earnings and for some workers it increases it. Second, Paxson and Sicherman (1996) report that the median wage ratio is positively correlated with skill level. This is consistent with the pattern in Figure 9: more educated workers tend to have more to gain from a second job than the least educated workers.

The empirical results above have established that (i) multiple jobholders hold two jobs; (ii) 
conditional on education, increasing real wages decreases multiple jobholding (over time with growth and in the cross section); (iii) higher skilled workers (using education as a proxy for skill) are more likely to work multiple jobs; (iv) hours worked are stable over time for single- and multiple jobholders, regardless of their skills; and (v) the number of children for employed individuals between age 20 and 55 decreased for the least educated and increased for the most educated, and it is an important determinant of the likelihood that a worker holds multiple jobs. The Probit models presented in Table 1 reveal that the effect of wages, education and children are significant after controlling for sex, marital status, age and race. Finally, we also established (vi) the earnings ratio of multiple jobholders to single jobholders is increasing in education, suggesting higher educated workers have a comparative advantage in the second job wage. In the rest of this paper we develop and use an equilibrium model of the labor market to understand the determinants of multiple jobholding. Guided by the results of this Section, we abstract from modeling sex, marital status, age and race to focus on the effect of productivity, education and the number of children.

\section{Model}

Time lasts for one period. Each worker has 1 unit of time to allocate between work and leisure. There are two types of jobs: full-time and part-time. A full-time job requires a fraction $n_{F}$ of time, and a part-time job requires a fraction $n_{P}$ of time. There are also two types of workers: skilled and unskilled. The proportion of skilled workers is exogenous and denoted by $\mu$.

\section{Production}

A representative firm produces output via a constant-returns-to-scale technology using the services of skilled labor and unskilled labor:

$$
Y=F\left(L_{S}, L_{U}\right)
$$

where $L_{S}\left(L_{U}\right)$ aggregates labor from full-time and part-time skilled (unskilled) workers:

$$
L_{x}=\left(z_{x, F} L_{x, F}^{\phi_{x}}+z_{x, P} L_{x, P}^{\phi_{x}}\right)^{1 / \phi_{x}}, x \in\{S, U\} .
$$


The parameters $z_{x, F}$ and $z_{x, U}$ are skill- and job-specific technology parameters, and $\phi_{x} \leq 1$ controls the elasticity of substitution between full-time and part-time labor. The terms $L_{x, F}$ and $L_{x, P}$ denote the total labor input from full-time and part-time workers with skill $x$, respectively. The firm's optimization problem is

$$
\max _{\left\{L_{x, F}, L_{x, P}\right\}} Y-\sum_{x \in\{S, U\}} w_{x, F} L_{x, F}-\sum_{x \in\{S, U\}} w_{x, P} L_{x, P}
$$

\section{Workers}

Workers have preferences defined over consumption and leisure. A typical worker's preferences are represented by the utility function

$$
U(c)+\alpha V(\ell)
$$

where $\alpha>0$, and where $c$ and $\ell$ stand for consumption and leisure, respectively. The functions $U$ and $V$ are increasing, twice-continuously differentiable and concave utility indexes.

Besides skills, workers are also differentiated by the intensity of their taste for leisure, $\alpha$. In each skill group there is a continuum of individuals indexed by $\alpha$. The cumulative distribution function for $\alpha$ is denoted $A(\alpha)$ and is identical for skilled and unskilled workers. Skilled and unskilled workers are endowed with $k_{S}$ and $k_{U}$ children, respectively. Each child imposes a goods cost denoted by $\theta$.

There are five types of employment a worker can choose from: one full-time job $(F)$, one part time job $(P)$, one full-time and one part-time job $(F P)$, two part-time jobs $(P P)$ and two full-time jobs $(F F)$. Let $e$ indicate a particular employment type: $e \in\{F, P, F P, P P, F F\}$. The value function of a worker $\alpha$ with skill $x$ and employment type $e$ is

$$
\begin{aligned}
& W_{x, e}(\alpha)=U\left(c_{x, e}\right)+\alpha V\left(\ell_{x, e}\right) \\
& \text { s.t. } \quad c_{x, e}+\theta k_{x}=y_{x, e} \\
& c_{x, e}, \ell_{x, e}>0
\end{aligned}
$$

where $c_{x, e}$ indicates consumption, $y_{x, e}$ is income and $\ell_{x, e}$ is leisure time. Table 2 shows income and leisure for all $x$ and $e$. The worker's labor supply is determined by 


\begin{tabular}{lll}
\hline $\mathrm{e}$ & $y_{x, e}$ & $\ell_{x, e}$ \\
\hline $\mathrm{F}$ & $w_{x, F} n_{F}$ & $1-n_{F}$ \\
$\mathrm{P}$ & $w_{x, P} n_{P}$ & $1-n_{P}$ \\
$\mathrm{FP}$ & $w_{x, F} n_{F}+w_{x, P} n_{P}$ & $1-n_{F}-n_{P}$ \\
$\mathrm{PP}$ & $2 w_{x, P} n_{P}$ & $1-2 n_{P}$ \\
$\mathrm{FF}$ & $2 w_{x, F} n_{F} v$ & $1-2 n_{F}$ \\
\hline
\end{tabular}

Table 2: Income and leisure for worker with skill $x$ by employment type

$$
\max _{e} W_{x, e}(\alpha)
$$

\subsection{Equilibrium}

An equilibrium is a set of prices $\left\{w_{x, j}\right\}$ for $(x, j) \in\{S, U\} \times\{F, P\}$ and an allocation of workers to jobs $\left\{p_{x, e}\right\}$ for $(x, e) \in\{S, U\} \times\{F, P, F P, P P, F F\}$ such that

1. The Firm optimizes given prices:

$$
F_{1}\left(L_{S}, L_{U}\right) \frac{\partial L_{S}}{\partial L_{S, j}}=w_{S, j}, \quad \text { for } j \in\{F, P\}
$$

and

$$
F_{2}\left(L_{S}, L_{U}\right) \frac{\partial L_{U}}{\partial L_{U, j}}=w_{U, j}, \quad \text { for } j \in\{F, P\}
$$

2. Workers optimize given prices:

The proportion of workers with skill $x$ optimally choosing employment type $e$ is

$$
p_{x, e}=\int_{\left\{\alpha: W_{x, e}(\alpha) \geq W_{x, e^{\prime}}(\alpha) \forall e^{\prime} \neq e\right\}} d A(\alpha) \text {. }
$$


3. The labor market clears:

$$
\begin{aligned}
& L_{S, F}=\mu\left(p_{S, F}+p_{S, F P}+2 p_{S, F F}\right) n_{F}, \\
& L_{S, P}=\mu\left(p_{S, P}+p_{S, F P}+2 p_{S, P P}\right) n_{P}, \\
& L_{U, F}=(1-\mu)\left(p_{U, F}+p_{U, F P}+2 p_{U, F F}\right) n_{F}, \\
& L_{U, P}=(1-\mu)\left(p_{U, P}+p_{U, F P}+2 p_{U, P P}\right) n_{P} .
\end{aligned}
$$

\subsection{Analysis}

In this Section we discuss the determination of labor supply and, specifically, the type of employment a worker chooses. We discuss first the effect of productivity, then the effect of the number of children. Finally, we analyze the conditions under which the model can simultaneously imply a negative correlation between multiple jobholdings and productivity (conditional on education), and a positive correlation between multiple jobholdings and education. Throughout the section we illustrate our discussion with a simplified version of a worker's decision problem: the choice between a full-time job $(e=F)$ versus a full- and a part-time job $(e=F P)$. This approach simplifies the discussion while still demonstrating the key mechanisms at work in the model.

The value functions for workers of skill $x \in\{S, U\}$ with type- $F$ employment and type- $F P$ employment are

$$
W_{x, F}(\alpha)=U\left(c_{x, F}\right)+\alpha V\left(\ell_{x, F}\right)
$$

and

$$
W_{x, F P}(\alpha)=U\left(c_{x, F P}\right)+\alpha V\left(\ell_{x, F P}\right),
$$

respectively. Figure 10 represents these value functions and two features are worth discussing. First, by construction the value functions are affine in $\alpha$ with an intercept given by $U$ and a slope given by $V$. Second, even though Figure 10 represents the value functions to be increasing in $\alpha$, this is only for representation's sake. The sign of the slope is the sign of $V$ and has no particular meaning.

Figure 10 shows that workers with $\alpha>\alpha_{x}^{*}$ choose to work one full-time job while workers with $\alpha<\alpha_{x}^{*}$ prefer to work both a full-time and a part-time job. This results from (i) the fact that the intercept of $W_{x, F}(\alpha)$ is lower than the intercept of $W_{x, F P}(\alpha)$; and (ii) the fact that the 


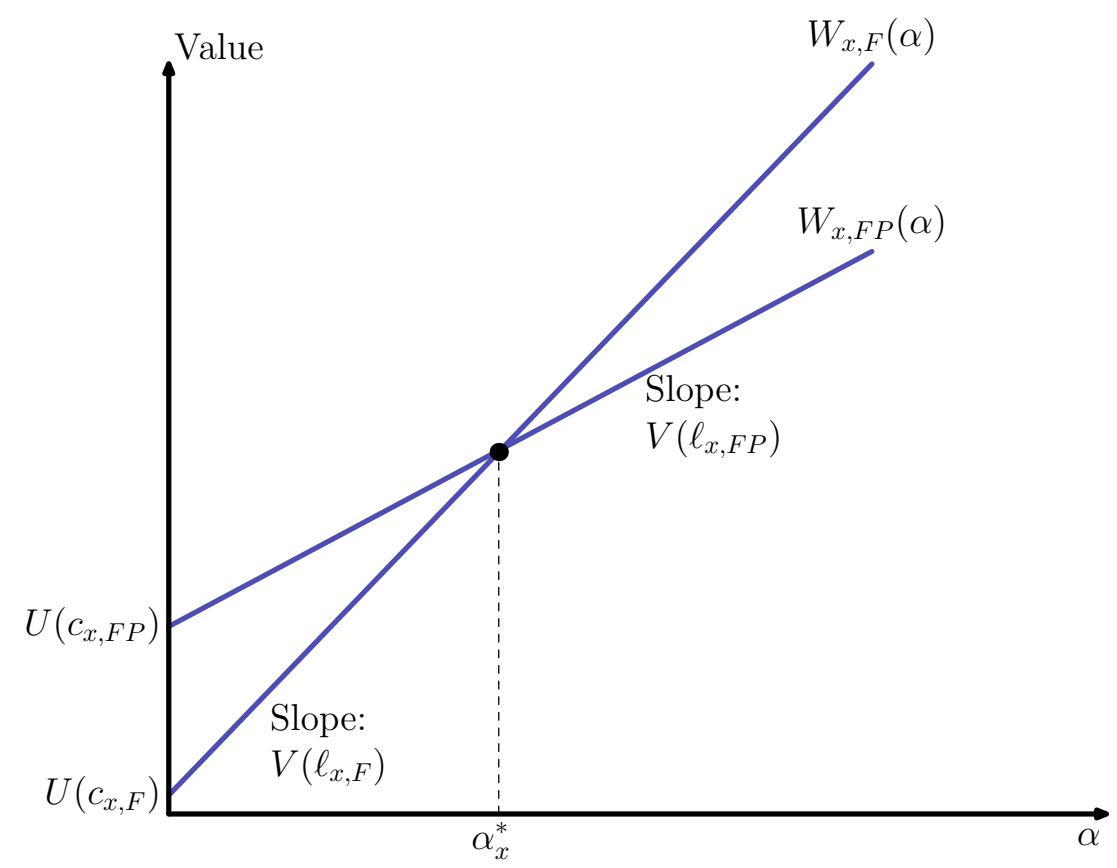

Figure 10: The determination of labor supply

slope of $W_{x, F}(\alpha)$ is larger than that of $W_{x, F P}(\alpha)$. To see that the first of these two conditions is generally satisfied, note that $c_{x, F}=w_{x, F} n_{F}-\theta k_{x}$ while $c_{x, F P}=w_{x, F} n_{F}+w_{x, F P} n_{P}-\theta k_{x}$. To see that the second condition is generally satisfied, it suffices to note that $\ell_{x, F}=1-n_{F}$ while $\ell_{x, F P}=1-n_{F}-n_{P}$. Hence $V\left(\ell_{x, F}\right)>V\left(\ell_{x, F P}\right)$.

The marginal worker, that is the worker who is indifferent between one full-time job and two jobs (one full-time and one part-time) is defined by $W_{x, F}\left(\alpha_{x}^{*}\right)=W_{x, F P}\left(\alpha_{x}^{*}\right)$. Using this condition, the critical value for $\alpha_{x}^{*}$ is given by:

$$
\alpha_{x}^{*}=\frac{U\left(w_{x, F} n_{F}+w_{x, P} n_{P}-\theta k_{x}\right)-U\left(w_{x, F} n_{F}-\theta k_{x}\right)}{V\left(1-n_{F}\right)-V\left(1-n_{F}-n_{P}\right)} .
$$

\section{The effect of productivity}

How does multiple jobholding change when $w_{x, F}$ and/or $w_{x, P}$ increase? Several effects must be discussed. First, suppose the ratio $w_{x, F} / w_{x, P}$ remains constant as both wages increase proportionally. Then, there are standard income and substitution effects at work. If the 
income effect dominates, workers tend to choose employment types requiring fewer hours of work. In the simple model presented here, this means a single, full-time job. If the substitution effect dominates, the opposite occurs. That is, workers tend to choose employment types requiring more hours of work; therefore, they are more likely to take two jobs as the wage increases.

In addition to the standard income and substitution effects there can also be "relative price effects" when the ratio $w_{x, F} / w_{x, P}$ changes. The term "relative price effect" refers to the relative wages between full-time and part-time jobs, not to the relative price of leisure and consumption, which of course changes even when $w_{x, F}$ and $w_{x, P}$ increase proportionally. Suppose, for instance, that $w_{x, F}$ is multiplied by a factor 2 and $w_{x, P}$ is multiplied by a factor 3. This could be viewed first as multiplying both wages by a factor 2 and, second, as increasing $w_{x, P}$ alone. The first part implies income and substitution effects as described earlier. In the second part, that is when $w_{x, P}$ alone increases there is (i) a standard income effect, again, because the worker becomes richer; (ii) a standard substitution effect, again, because leisure becomes more expensive; and (iii) what we refer to as the "relative price effect" which indicates that time spent working the full time job is becoming relatively more expensive. The latter effect makes part-time labor more attractive and induces workers to choose to work part-time. In the simple model above, this means workers tend to prefer working two jobs to one.

In the general model with all five employment arrangements, the preference for two jobs to one job when $w_{x, F} / w_{x, P}$ decreases may or may not obtain. It depends on the relative strength of the income and substitution effects. The "relative price effects" imply that when $w_{x, F} / w_{x, P}$ decreases, workers begin to favor the part-time job relative to the full-time job. If the standard income effect is strong enough, workers would prefer to hold only one, part-time job. If, instead, the standard substitution effect is strong enough, workers would prefer to hold two part-time jobs.

The interplay between income, substitution and relative price effects is, ultimately, a quantitative question addressed in Section 4. For now, we show formally how these effects operate in our simplified model. We start with a proportional increase in both $w_{x, F}$ and $w_{x, P}$. Suppose 
that $w_{x, P}=\rho w_{x, F}$ and that $\rho$ is a positive constant. Equation (4) implies

$$
\left.d \alpha_{x}^{*}\right|_{\frac{w_{x, P}}{w_{x, F}=\rho}}=\frac{U^{\prime}\left(c_{x, F P}\right)\left(1+\rho \frac{n_{P}}{n_{F}}\right)-U^{\prime}\left(c_{x, F}\right)}{V\left(\ell_{x, F}\right)-V\left(\ell_{x, F P}\right)} n_{F} d w_{x, F}
$$

The sign of this expression is the sign of the numerator. When $w_{x, P}=\rho w_{x, F}$, consumption of the two types of workers is related by

$$
c_{x, F P}=c_{x, F}\left(1+\rho \frac{n_{P}}{n_{F}}\right)+\theta k_{x} \rho \frac{n_{P}}{n_{F}} .
$$

The numerator in Equation (5) becomes

$$
U^{\prime}\left(c_{x, F}\left(1+\rho \frac{n_{P}}{n_{F}}\right)+\theta k_{x} \rho \frac{n_{P}}{n_{F}}\right)\left(1+\rho \frac{n_{P}}{n_{F}}\right)-U^{\prime}\left(c_{x, F}\right)
$$

Suppose the utility index $U$ is such that $U^{\prime}(c z) z$ is a decreasing function of $z$. We claim this type of utility index implies that the income effect from a change in wages dominates the substitution effect. We prove this claim in Appendix B. Note that if $U^{\prime}(c z) z$ is decreasing in $z$ and if $\theta=0$, the expression in (6) is negative. Note also that the first element in (6) is decreasing in $\theta$, therefore the expression in Equation (6) is negative for all $\theta \geq 0$ whenever $U^{\prime}(c z) z$ is decreasing in $z$.

This implies that when the income effect dominates, $\alpha_{x}^{*}$ decreases whenever wages increase proportionally. The interpretation of this result is that workers seek to increase their leisure when wages increase, and they can achieve this by using the extensive margin of employment and, in particular, by choosing to work only one job.

Next we turn to the individual effects of $w_{x, F}$ and $w_{x, P}$ which are described in Equation (7).

$$
d \alpha_{x}^{*}=\frac{1}{V\left(\ell_{x, F}\right)-V\left(\ell_{x, F P}\right)}\left[\left(U^{\prime}\left(c_{x, F P}\right)-U^{\prime}\left(c_{x, F}\right)\right) n_{F} d w_{x, F}+U^{\prime}\left(c_{x, F P}\right) n_{P} d w_{x, P}\right] .
$$

Here an increase in $w_{x, F}$ alone reduces $\alpha_{x}^{*}$, which therefore increases the number of workers with one job (in this simplified model). This follows from the fact $c_{x, F}<c_{x, F P}$. Similarly, an increase in $w_{x, P}$ alone increases $\alpha_{x}^{*}$, which therefore increases the number of workers with two jobs (in this simplified model). 


\section{The effect of children}

In our model, children are exogenously endowed to each worker and they impose a goods cost. Thus, a decrease in the number of children is akin to an increase in income, holding all relative prices constant. Since leisure is a normal good, workers with fewer children tend to work fewer hours, which is achieved by adjusting their labor supply at the extensive margin. Thus, the decrease in the number of children among unskilled workers (see Figure 5) is conducive to a decline in the fraction of multiple jobholders while the increase for skilled workers has the opposite effect.

In the context of the simple example in this Section, the effect of a change in the number of children is

$$
\frac{d \alpha_{x}^{*}}{d k_{x}}=-\theta \frac{U^{\prime}\left(c_{x, F P}\right)-U^{\prime}\left(c_{x, F}\right)}{V\left(\ell_{x, F}\right)-V\left(\ell_{x, F P}\right)}>0,
$$

where the inequality follows from the facts that $c_{x, F}<c_{x, F P}$ and that $\ell_{x, F}>\ell_{x, F P}$. Thus, a decrease in the number of children reduces $\alpha_{x}^{*}$, and thus decreases the proportion of workers with two jobs. This effect is qualitatively consistent with the estimated coefficients of the Probit models $1 M, 1 A, 2 M$ and $3 M$ displayed in Table 1

\section{Comparative advantage}

In Section 2 we pointed out an apparent contradiction. On the one hand, conditional on education the most productive workers are the least likely to hold multiple jobs; on the other hand the most educated workers are the most likely to hold multiple jobs. Our model reconciles this apparent contradiction through the following mechanisms.

First, we have shown that as a long as preferences are such that the income effect from wages dominates the substitution effects, the most productive workers seek to work fewer hours. This is achieved by adjusting labor supply at the extensive margin, working only one job instead of two. This mechanism explains the time series correlation of multiple jobholdings with productivity, as well as the cross-sectional correlation, conditional on education.

Second, to see how the model explains the higher prevalence of multiple jobholders among skilled (i.e. high education) workers, we show the conditions under which $\alpha_{S}^{*} / \alpha_{U}^{*}>1$ in the simplified model. To do this, we consider the special case where $U(c)=\left(1-\sigma_{C}\right)^{-1}(c-\bar{c})^{1-\sigma_{C}}$ with $\sigma_{C}>0$. In the quantitative analysis of Section 4 we use this functional form for $U$. It 
follows that

$$
\frac{\alpha_{S}^{*}}{\alpha_{U}^{*}}=\underbrace{\left(\frac{w_{S, F}}{w_{U, F}}\right)^{1-\sigma_{C}}}_{A} \underbrace{\frac{\left(n_{F}+\frac{w_{S, P}}{w_{S, F}} n_{P}-\frac{\theta_{K} k_{S}-\bar{c}}{w_{S, F}}\right)^{1-\sigma_{C}}-\left(n_{F}-\frac{\theta_{K} k_{S}-\bar{c}}{w_{S, F}}\right)^{1-\sigma_{C}}}{\left(n_{F}+\frac{w_{U, P}}{w_{U, F}} n_{P}-\frac{\theta_{K} k_{U}-\bar{c}}{w_{U, F}}\right)^{1-\sigma_{C}}-\left(n_{F}-\frac{\theta_{K} k_{U}-\bar{c}}{w_{U, F}}\right)^{1-\sigma_{C}}}}_{B} .
$$

Two points are worth noting. First, given the college premium, that is $w_{S, F} / w_{U, F}>1$, the features of $A$ depend on the utility parameter $\sigma_{C}$. If $\sigma_{C}>1$, then $A<1$ and is decreasing in $w_{S, F} / w_{U, F}$. If $\sigma_{C} \in(0,1)$, then $A>1$ and is increasing in $w_{S, F} / w_{U, F}$. This obtains because when $\sigma_{C}>1$, the income effect of an increase in $w_{S, F}$ dominates the substitution effect, causing skilled workers to work less. This is achieved by not taking a second job; as a result, $\alpha_{S}^{*}$ decreases. When $\sigma_{C} \in(0,1)$ the substitution effect dominates and $\alpha_{S}^{*}$ increases in response to an increase in $w_{S, F}$. Second, part $B$ of Equation (9) is increasing in $w_{S, P} / w_{S, F}$ and decreasing in $w_{U, P} / w_{U, F}$.

Suppose that $\sigma_{C}>1$ (as is the case in our quantitative analysis of Section 4). It follows from the discussion above that $\alpha_{S}^{*} / \alpha_{U}^{*}>1$ whenever $w_{S, P} / w_{S, F}$ is sufficiently large relative to $w_{U, P} / w_{U, F}$. We refer to the inequality

$$
\frac{w_{S, P}}{w_{S, F}}>\frac{w_{U, P}}{w_{U, F}}
$$

as describing a comparative advantage of skilled workers over unskilled workers in part time jobs.

When $\sigma_{C}>1$ the "college-premium" effect embodied in $A$ tends to reduce the prevalence of multiple jobholders among college educated workers in the cross-section. The "comparative advantage" effect embodied in $B$ acts in the opposite direction, however. With a large enough comparative advantage, the model reconciles the higher prevalence of multiple jobholders among college-educated workers in the cross-section, with the negative correlation between multiple jobholding and productivity in both the time series and the cross-section (conditional on education). ${ }^{9}$

\footnotetext{
${ }^{9}$ When $\sigma_{C} \in(0,1)$ both the "college-premium" and the "comparative advantage" effects operate in the same direction. Therefore the comparative advantage necessary to reconcile the cross-section and time series observations is lower.
} 


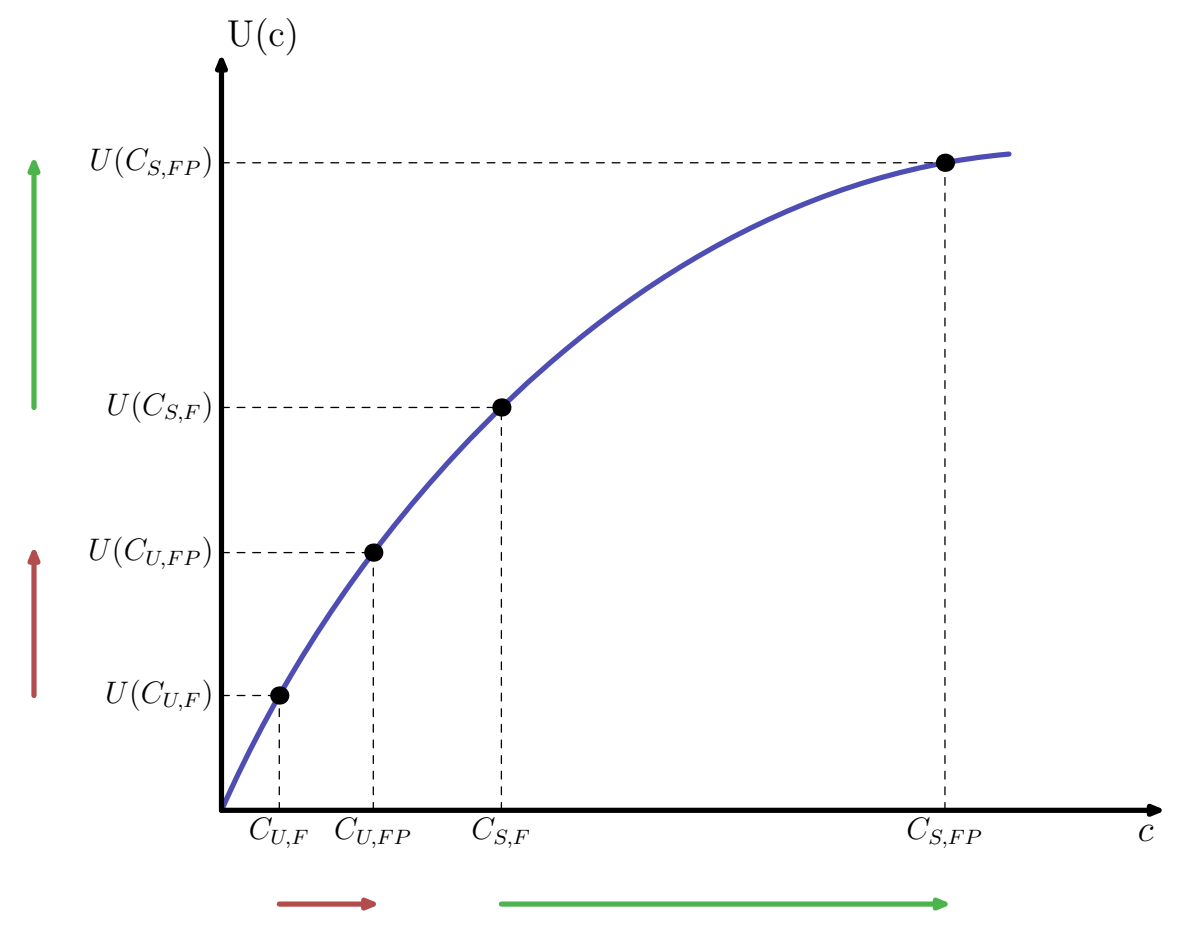

Figure 11: The comparative advantage of skilled workers in part-time jobs

The economics behind this discussion are illustrated in Figure 11. Consider two workers, one skilled and the other unskilled. Suppose that they both work one full-time job and have identical preferences, i.e., the same $\alpha$. Under what conditions would the skilled worker take a second job while the unskilled worker would not? The cost of taking the second job, forgone leisure time, is the same for each worker. The benefit, however, is not the same. The skilled worker's marginal utility is lower because of the skill premium. Thus, in order for the utility gain from the second job to be larger for the skilled worker (green vertical arrow) than for the unskilled (red vertical arrow), the associated consumption gain must be larger for the skilled worker relative to the unskilled. Hence the need for a comparative advantage of skilled workers in part time jobs.

We also note that the presence of children matters in this discussion. To see this in Figure 11, suppose the number of children increases, from 0 to $k_{U}$ for an unskilled worker, and from 0 to $k_{S}$ for a skilled worker. Further assume that $k_{S}<k_{U}$. Both $c_{S, F}$ and $c_{S, F P}$ move to the left by $\theta k_{S} / w_{S, F}$ while $c_{U, F}$ and $c_{U, F P}$ move to the left by $\theta k_{U} / w_{U, F}$. Note that the total cost of children is higher for the unskilled worker: $\theta k_{U} / w_{U, F}>\theta k_{S} / w_{S, F}$ since $k_{U}>k_{S}$ and $w_{S, F}>w_{U, F}$. Thus, the benefit of a second job increases for the unskilled worker more than 
for the skilled worker. This implies that a higher comparative advantage is necessary for the skilled worker to choose multiple jobs while the unskilled worker would not. ${ }^{10}$

\section{Quantitative Analysis}

Our quantitative analysis proceeds in several steps. First, we calibrate our model to the U.S. data in 1994 - the first year for which the CPS reports statistics on multiple jobholders. We discipline the parameters of the model by targeting the proportion of multiple jobholders by education, as well as the distribution of multiple jobholders across different employment types. We also target the college premium, and a measure of the goods cost of children.

Second, we compute a new equilibrium corresponding to the U.S. data in 2017. There are three differences between the 1994 (initial) equilibrium and the 2017 (final) equilibrium: (i) productivity parameters change in such a way as to reproduce income growth in the U.S. economy between 1994 and 2017, and the increase in the college premium; (ii) the number of children for high school- and college-educated workers changes as in the U.S. data; and (iii) the proportion of college-educated workers changes as in the U.S. data.

Third, we compare the model's predicted evolution of multiple jobholding to the actual U.S. data. We also conduct a decomposition of the contribution of changes in the aforementioned variables: (i) productivity, (ii) the number of children and (iii) educational attainment.

\subsection{Calibration}

We interpret a time period as lasting one week, and assume that there is a total of $7 \times(24-$ $8)=112$ hours available for either work or leisure in the week. A full-time job requires 40 hours, implying $n_{F}=40 / 112=0.36$. We use Figure 3 to justify that a part-time job requires 10 hours of work; therefore, we set $n_{P}=10 / 112=0.09$. According to the CPS data, in 1994 56 percent of workers had at least some college education. Thus, we set $\mu_{S}=0.56$. The data also show that college-educated workers ages 20-55 had 1.15 children under 18 years of age. High school-educated workers ages $20-55$ had 1.22 children under the age of 18 . Thus, we set $k_{S}=1.15$ and $k_{U}=1.22$. We choose the following functional form for the production

\footnotetext{
${ }^{10}$ Note that $k_{S}<k_{U}$ is not necessary for this result to hold.
} 
function

$$
Y=\left(L_{S}^{\eta}+L_{U}^{\eta}\right)^{1 / \eta} .
$$

The elasticity of substitution between skilled and unskilled labor is $1 /(1-\eta)$. We follow Goldin and Katz (2007) and use an elasticity of substitution of 1.6, implying $\eta=1-1 / 1.6$. We use the same value for $\phi_{S}$ and $\phi_{U}$, which determine the elasticity of substitution between full-time and part-time labor for skilled and unskilled labor, respectively (Equation 2). Note that we do not weight $L_{S}^{\eta}$ and $L_{U}^{\eta}$ in Equation (11). This is because such weights could not be distinguished from the the productivity parameters $z_{x, j}$ for $(x, j) \in\{S, U\} \times\{F, P\}$.

For the utility function we specify:

$$
U(c)=\frac{(c-\bar{c})^{1-\sigma_{C}}}{1-\sigma_{C}} \text { and } V(\ell)=\frac{\ell^{1-\sigma_{L}}}{1-\sigma_{L}},
$$

where $\sigma_{C}, \sigma_{L}>0$. The distribution of $\alpha$ is assumed to be log-normal:

$$
\ln (\alpha) \sim N\left(\mu_{\alpha}, \sigma_{\alpha}\right) .
$$

This implies 10 parameters to calibrate:

$$
\omega=\left\{\sigma_{C}, \sigma_{L}, \bar{c}, \mu_{\alpha}, \sigma_{\alpha}, z_{S, F}, z_{S, P}, z_{U, F}, z_{U, P} \theta_{K}\right\} .
$$

These parameters are calibrated to the following moments from the data: the proportion of two jobholders by education, the proportion of workers with two part-time jobs, and the proportion of skilled and unskilled workers with a full- and a part-time job. We also target the hourly earnings ratio between workers with one or two jobs, by education levels and the college premium. Finally, we target the goods cost of a child as fraction of a household's 
income. Thus there exists 10 moments to calibrate the 10 parameters. Practically, we define

$$
M(\omega)=\left[\begin{array}{c|c}
p_{S, F P}+p_{S, P P}+p_{S, F F}-7.43 \% & 1 \\
p_{U, F P}+p_{U, P P}+p_{U, F F}-4.32 \% & 2 \\
\mu_{S} p_{S, P P}+\left(1-\mu_{S}\right) p_{U, P P}-2.10 \% & 3 \\
p_{S, F P}-3.80 \% & 4 \\
p_{U, F P}-2.10 \% & 5 \\
e_{S, 2} / e_{S, 1}-0.93 & 6 \\
e_{U, 1} / e_{S, 1}-0.67 & 7 \\
e_{U, 2} / e_{S, 1}-0.67 & 8 \\
w_{S, F} / w_{U, F}-1.55 & 9 \\
\theta_{K}\left(\mu_{S} k_{S}+\left(1-\mu_{S}\right) k_{U}\right) / y-0.2 & 10
\end{array}\right.
$$

where $y=\mu_{S} \sum_{e} p_{S, e} y_{S, e}+\left(1-\mu_{S}\right) \sum_{e} p_{U, e} y_{U, e}$, is the average worker's income. We then solve

$$
\min _{\omega} M(\omega)^{\prime} M(\omega) .
$$

A few comments are in order at this stage. The first two rows of $M(\omega)$ indicate the difference between the model's implied proportions of skilled and unskilled workers with two jobs, and the corresponding empirical moment in 1994. The third row relates to the proportion of workers with two part-time jobs - namely the difference between the statistics implied by the model and its empirical counterpart. These statistics are calculated using the CPS data, where a part-time, single jobholder is defined as a worker with only one job with less than 35 hours per week. Rows 4 and 5 relate to the proportions of workers, skilled and unskilled, with one full- and one part-time job.

Rows 6-9 relate to the wage ratios between various categories of workers. We define the following variables: the average hourly earnings of a worker with skill $x$ and one job: $e_{x, 1}$, and the hourly earnings of a worker with skill $x$ and two jobs: $e_{x, 2}$. These averages are

$$
e_{x, 1}=\frac{1}{p_{x, F}+p_{x, P}}\left[p_{x, F} w_{x, F}+p_{x, P} w_{x, P}\right]
$$

and

$$
e_{x, 2}=\frac{1}{p_{x, F P}+p_{x, P P}+p_{x, F F}}\left[p_{x, F P} \frac{w_{x, F} n_{F}+w_{x, P} n_{P}}{n_{F}+n_{P}}+p_{x, P P} w_{x, P}+p_{x, F F} w_{x, F}\right] .
$$


The data reveal that in 1994, the relative hourly earnings of workers were $e_{S, 2} / e_{S, 1}=0.93$, $e_{U, 1} / e_{S, 1}=0.67$ and $e_{U, 2} / e_{S, 1}=0.67 .{ }^{11}$ We use these statistics in row 6-8 of $M(\omega)$. For row 9 we define a measure of the college premium as the ratio of hourly earnings between workers with at least some college and workers with at most a high-school degree (each holding a single, full time job). The data indicate this ratio to be 1.55 in 1994, and the model's counterpart of this ratio is $w_{S, F} / w_{U, F}$. Finally, row 10 indicates that the cost of a child represents 20 percent of the household's income - see Greenwood et al. (2017, Tables 1 and 2).

Although the parameters are determined simultaneously through the minimization program in (13), some parameters matter more than others for certain moments. Heuristically, the 3 utility parameters $\left(\sigma_{C}, \sigma_{L}, \bar{c}\right)$ and the 2 distribution parameters $\left(\mu_{\alpha}, \sigma_{\alpha}\right)$ have a first-order effect on the first five moments in Equation (12); the value of the technology parameters $\left(z_{S, F}, z_{S, P}, z_{U, F}, z_{U, P}\right)$ have a first-order effect on targets 6-9 in Equation (12); and the value of $\theta_{K}$ has a first-order effect on target 10 in Equation (12).

First note that the parameters governing the curvature of the utility index, $U$, determine the comparative advantage of skilled workers - see Figure 11. Thus, utility and distribution parameters are informed by the proportion of multiple jobholders in different employment types in the data (row 1-3 in Equation 12), and by the fact that more skilled workers work a FP-type job than unskilled workers in the data (row 4-5 in Equation 12). Given distribution parameters and wages, Equations (4) and (9) represent mappings from the utility parameters $\sigma_{C}, \sigma_{L}$ and $\bar{c}$ to the proportions of multiple jobholders in different employment types in the data. We also note that the curvature of $U$, disciplined by the data on multiple jobholders across education groups, also determines the relative magnitude of the income and substitution effects. If the calibrated values of $\sigma_{C}$ and $\bar{c}$ were 1 and 0 , respectively, then the income and substitution effects cancel out. Thus, our calibration strategy has implications for the time-series behavior of our model which we discuss in Section 4.2.

Second, the mapping from technology parameters to relative earnings follows from the fact that wages are determined by marginal products. In particular, the college premium data imposes discipline on $z_{S, F}$ and $z_{U, F}$ which, in part, determine the model-generated college premium $w_{S, F} / w_{U, F}$. Finally, the link between the cost of children and the parameter $\theta_{K}$ is immediate.

\footnotetext{
${ }^{11}$ See Appendix A, Figure A.3.
} 
Table 3: Calibrated parameters

\begin{tabular}{ll}
\hline Preferences & $\sigma_{C}=+1.56, \sigma_{L}=+1.24, \bar{c}=-0.10$ \\
& $\mu_{\alpha}=+1.14, \sigma_{\alpha}=+0.51$ \\
Technology & $\eta=+0.38, \phi_{S}=+0.38, \phi_{U}=+0.38$ \\
& $z_{S, F}=+0.74, z_{S, P}=+0.05$ \\
& $z_{U, F}=+0.44, z_{U, P}=+0.01$ \\
Worktime & $n_{F}=+0.36, n_{P}=+0.09$ \\
Children & $k_{S}=+1.15, k_{U}=+1.22, \theta_{K}=+0.05$ \\
\hline
\end{tabular}

Table 4: Model fit

\begin{tabular}{lrrr}
\hline Moment & Model & Data & Target \\
\hline Proportion of workers with two jobs & & & \\
$\quad$ Skilled & $7.49 \%$ & $7.4 \%$ & Yes \\
Unskilled & $4.29 \%$ & $4.3 \%$ & Yes \\
FP (all) & $3.01 \%$ & $3.0 \%$ & \\
PP (all) & $2.04 \%$ & $2.1 \%$ & Yes \\
FF (all) & $0.98 \%$ & $0.6 \%$ & \\
Skilled FP & $3.76 \%$ & $3.8 \%$ & Yes \\
Unskilled FP & $2.12 \%$ & $2.1 \%$ & Yes \\
Skilled PP & $3.31 \%$ & $2.6 \%$ & \\
Unskilled PP & $0.53 \%$ & $1.5 \%$ & \\
$\quad$ Skilled FF & $0.42 \%$ & $0.7 \%$ & \\
Unskilled FF & $1.65 \%$ & $0.5 \%$ & \\
Earnings relative & & & \\
skilled workers with one job & & & \\
$\quad$ workers with two jobs, skilled & 0.81 & 0.93 & Yes \\
$\quad$ workers with two jobs, unskilled & 0.58 & 0.67 & Yes \\
$\quad$ workers with one jobs, unskilled & 0.65 & 0.67 & Yes \\
College premium & 1.54 & 1.55 & Yes \\
Cost of children & 0.21 & 0.20 & years \\
\hline
\end{tabular}


Table 3 reports the model's calibrated parameters and Table 4 compares model predictions with data for targeted and non-targeted moments. The model reproduces the ranking of the prevalence of multiple jobholders across education: college-educated workers are more likely to be multiple jobholders because they have a comparative advantage in part-time jobs relative to high school-educated workers - see Section 3.2. The model also reproduces the higher prevalence of skilled workers among workers with two part-time jobs, a nontargeted moment. Finally, the model matches well the relative hourly earnings across various employment type and the skill premium. Notice that the model implies fewer skilled than unskilled workers in the FF category. This is a by-product of the income effect that pushes skilled workers to seek to work fewer hours, relative to unskilled workers. Workers with two full-time jobs represent a small (less than 1 percent) fraction of all workers; therefore, amending the model to match the ordering of FF workers across skill groups is not an appealing direction of improvement.

Figure 12 displays aggregate labor supply, measured in hours, for skilled and unskilled workers. We make several observations. First, focus on the red lines on each surface. Along these lines, $w_{x, F}$ and $w_{x, P}$ change proportionately, maintaining $w_{x, P} / w_{x, F}$ at the appropriate equilibrium value. As workers face increasing wages and a constant relative price of full-time versus part-time jobs, total hours worked decreases. This is because the income effect from an increase in wages dominates and workers seek to reduce their hours by selecting into employment types requiring fewer hours.

Second, note that labor supply is higher for unskilled workers than for skilled workers, while skilled workers are more likely to hold multiple jobs. Again, this results from the income effect: unskilled workers seek to work longer hours because they are paid less on average. They achieve this by selecting into employment types that require long hours, one full-time job, one full-time and one part-time job or two full-time jobs. Skilled workers, on the other hand, seek to work fewer hours, but are enticed to choose multiple jobs by their comparative advantage in part-time jobs. Thus, two part-time jobs are more prevalent among skilled workers. Since hours on two part-time jobs do not add up to the hours of one full-time job, this tends to lower the total hours supplied by skilled workers.

Before turning to several counterfactual experiments, we conduct a few additional calculations. Specifically, we examine how sensitive multiple jobholding is with respect to the exogenous parameters. Understanding these sensitivities is enlightening because, the experiments in Section 4.2 change the exogenous variables in ways consistent with data. As a 


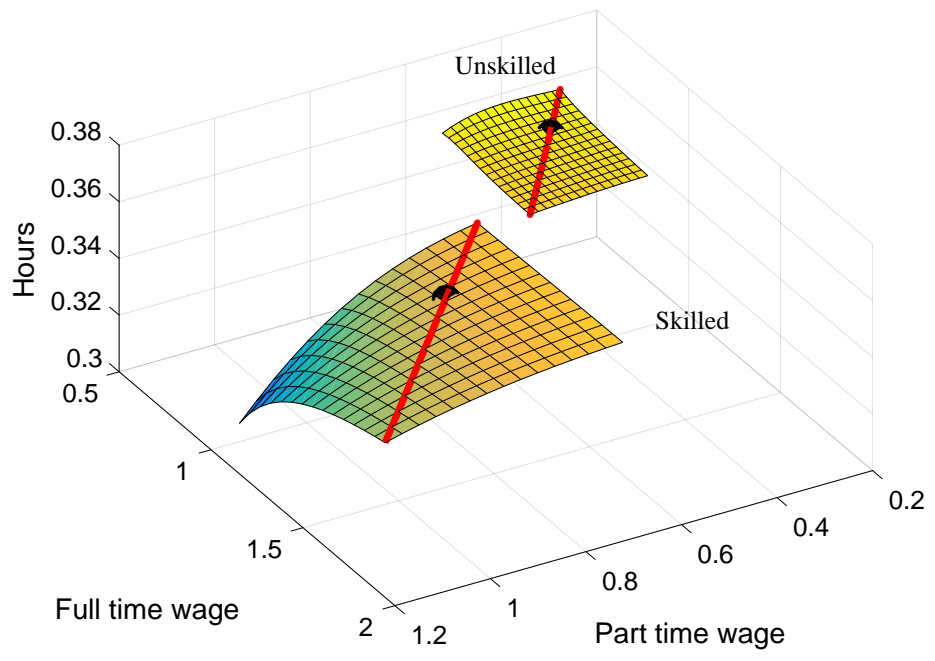

A - Initial equilibrium

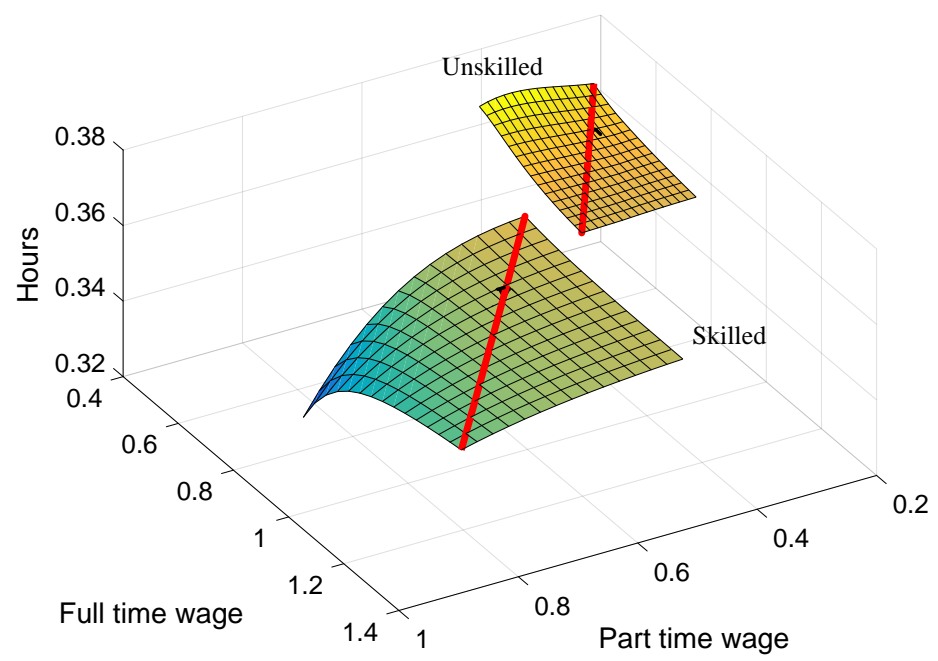

\section{B - Final equilibrium}

Figure 12: Labor supply in calibrated model

Note: The figure shows the labor supply functions of skilled and unskilled workers, measured in hours. The black dots indicate the equilibrium solution. The red line indicates a constant (at equilibrium value) $w_{x, P} / w_{x, F}$ ratio for $x \in\{S, U\}$.

Source: Authors' calculations. 
Table 5: The elasticity of multiple jobholding, percent

\begin{tabular}{lrr}
\hline Variable & Skilled & Unskilled \\
\hline$z_{S, F}$ & -2.22 & -1.05 \\
$z_{S, P}$ & 1.04 & -0.01 \\
$z_{U, F}$ & -0.34 & -2.39 \\
$z_{U, P}$ & -0.00 & 0.78 \\
$\mu$ & 0.29 & -0.92 \\
$k_{S}$ & 0.37 & -0.02 \\
$k_{U}$ & -0.00 & 1.13 \\
\hline
\end{tabular}

Note: The table reports the percentage change in the fraction of multiple jobholders after a 1 percent increase in a particular exogenous variable.

Source: Authors' calculations.

result, it is difficult to assess whether a variable has a "small" effect because the elasticity of the model with respect to this variable is "small," or because the change in the variable is "small" in the data.

To accomplish this, we consider a 1 percent change relative to calibrated value for each exogenous variable. Namely, we multiply each exogenous variable by 1.01, leaving the other variables constant. We then compute the relative (in percent) change in the proportion of multiple jobholders for each education group. Table 5 reports the results.

Two features from Table 5 are worth noting. First, an increase in $z_{S, F}\left(z_{U, F}\right)$ reduces the proportion of skilled (unskilled) multiple jobholders via the mechanism described in Section 3.2 ; i.e. more workers seek to work one, full-time job when full-time jobs become more productive (see Equation (7)). Second, an increase in the proportion of skilled workers, $\mu$, increases the proportion of skilled multiple jobholders and reduces the proportion of unskilled multiple jobholders. This obtains because, all else equal, when there are more skilled workers and fewer unskilled workers, wages decrease for the skilled and increase for the unskilled. The income effect then induces the skilled to work longer hours (and therefore to work more jobs) and the unskilled to work fewer hours (and therefore to work fewer jobs). 


\subsection{Experiments}

We now use the calibrated model to conduct experiments. In our baseline experiment we compute a final equilibrium which we assimilate to the U.S. in 2017, and compare it to the initial equilibrium (1994). Three sets of parameters change between the 1994 and the 2017 equilibria. First, the number of children increases for the skilled from $k_{S}=1.15$ to $k_{S}=1.16$ and decreases from $k_{U}=1.22$ to $k_{U}=1.18$ for the unskilled. Second, the proportion of college-educated workers increases from 56 to 66 percent, thus $\mu_{S}=0.66$ in the final equilibrium. Finally, productivity changes. To discipline the change in productivity, we impose that productivity growth is the same for workers of a given skill, regardless of whether their employment is full-time of part-time. Denoting the growth rate of productivity for skilled and unskilled as $g_{S}$ and $g_{U}$, respectively:

$$
\begin{aligned}
& \left.z_{S, j}\right|_{\text {final }}=\left.\left(1+g_{S}\right) z_{S, j}\right|_{\text {initial }} \text { for } j \in\{F, P\} \\
& \left.z_{U, j}\right|_{\text {final }}=\left.\left(1+g_{U}\right) z_{U, j}\right|_{\text {initial }} \text { for } j \in\{F, P\} .
\end{aligned}
$$

We set $g_{x}$ to satisfy two conditions in the final equilibrium of our baseline experiment. First output is 40 percent higher than in the initial equilibrium. This corresponds to a growth rate of 1.4 percent per year between 1994 and 2017: 1.014 $4^{24}=1.4$. Second, the college premium is 1.66 in the final equilibrium, as revealed by CPS data in 2017. These conditions imply that $g_{S}=0.25$ and $g_{U}=-0.14$. Thus, the productivity of skilled workers increases (by $0.94 \%$ per year) while that of unskilled workers decreases (by $0.63 \%$ per year). It is important to note, however, that all wages increase between the initial and final steady state. This is because, despite lower productivity the marginal product of unskilled workers does not decline. There are two reasons for this: there are more skilled workers in the final equilibrium, and they are more productive. Both effects contribute to the increase in the marginal productivity of unskilled workers.

The first column of Table 6 reports the results of of our baseline experiment. To understand these figures consider skilled workers. The model implies that in the initial equilibrium $7.49 \%$ of them are multiple jobholders - this is calibrated to the U.S. data in 1994. In the final equilibrium this number is $6.44 \%$. In the U.S. data the corresponding figures are 7.43 and 5.80 , respectively. The model-generated decline represents then $(6.44-7.49) /(5.80-7.43) \simeq$ $64.1 \%$ of the actual decline. That is the figure reported in Table 6. For unskilled workers the model implies a decline accounting for $96.7 \%$ of the observed decline. We note that, in the 
Table 6: Experiments

\begin{tabular}{lrrrrrrr}
\hline & All & $\begin{array}{r}\text { Prod. } \\
\text { only }\end{array}$ & $\begin{array}{r}\text { Fert. } \\
\text { only }\end{array}$ & $\begin{array}{r}\text { Educ. } \\
\text { only }\end{array}$ & $\begin{array}{r}\text { Prod. } \\
+ \text { Educ. }\end{array}$ & $\begin{array}{r}\text { Prod. } \\
+ \text { Fert. }\end{array}$ & $\begin{array}{r}\text { Educ. } \\
+ \text { Fert. }\end{array}$ \\
& $(1)$ & $(2)$ & $(3)$ & $(4)$ & $(5)$ & $(6)$ & $(7)$ \\
\hline Skilled & $\mathbf{6 4 . 1}$ & 72.7 & -1.6 & -30.3 & 64.5 & 72.5 & -32.3 \\
Unskilled & $\mathbf{9 6 . 7}$ & 7.0 & 14.4 & 74.7 & 87.8 & 21.0 & 84.4 \\
\hline
\end{tabular}

Note: The table reports the decline in the proportion of multiple jobholders implied by the model, as a percentage of the actual decline between 1994 and 2017. Figures in bold represent our baseline results. Source: Authors' calculations.

final equilibrium, the model preserves the higher prevalence of multiple jobholders among skilled workers, (6.4 percent), than among unskilled workers (3.2 percent). That is, skilled workers retain their comparative advantage in part-time jobs over unskilled workers.

Next, consider the following additional experiments. In the first three experiments we change only one type of variable at a time: either we change the productivity parameters ("Prod. only"), or the number of children ("Fert. only") or educational attainment ("Educ. only"). Columns 2-4 of Table 6 report the change in the proportion of multiple jobholders in each case, relative to the actual decline in the U.S. data.

The "Prod. only" experiment reveals that the effect of productivity is large for skilled workers. With productivity only, the decline in the proportion of skilled multiple jobholders is stronger than in the baseline experiment, and accounts for $72.7 \%$ of the actual decline, instead of $64.1 \%$. For unskilled workers, it is the opposite. Productivity alone implies a smaller decline in the proportion of unskilled multiple jobholders.

To understand these effects recall that, in the baseline experiment, all wages increase, including those of unskilled workers despite the decline in their productivity, i.e., $g_{U}<0$. Recall also that one reason for the increase in the wages of unskilled workers in the baseline experiment is the increase in educational attainment. This effect is absent from the "Prod. only" experiment and, therefore, the increase in wages for unskilled worker is small (compared with the baseline) in the "Prod. only" experiment. As a result, the income effect is small (compared with the baseline) for unskilled workers, and the decline in moonlighting is small. A corollary of this argument is that the increase in wages for skilled workers in the 
"Prod. only" experiment is larger than in the baseline. This is precisely because there is no increase in educational attainment. Thus, the income effect is stronger for skilled workers.

Contemplate now the "Educ. only" experiment. The effect of education alone is large, and its direction is opposite for skilled and unskilled workers. This obtains because, as the proportion $\left(\mu_{S}\right)$ of skilled workers increases while productivity remains constant, skilled wages decrease and unskilled wages increase. Thus, the income effect induces skilled workers to seek longer hours which may be achieved by working multiple jobs. Hence the increase in the proportion of skilled multiple jobholders. The reverse mechanism is at work for unskilled workers. Note that, for unskilled workers, the increase in wage is not as large as in the baseline because skilled workers are not becoming more productive. Thus, in the "Educ.

only" experiment, the decline of unskilled multiple jobholders is not as important as in the baseline.

The decline in the number of children ("Fert. only") for unskilled workers (from 1.22 to 1.18) accounts, on its own, for $14.4 \%$ of the decline in the prevalence of multiple jobholders among the unskilled. This leads us to conclude that children are, indeed, a significant determinant in the decision to hold a second job. For skilled workers the number of children actually increased (see Bar et al., 2018) from 1.15 to 1.16, which by itself increases the proportion of multiple jobholders.

The magnitudes in the "Prod. only" and the "Educ. only" experiments are large (with opposite signs for skilled vs. unskilled workers in "Educ. only"). Given this, we consider a fourth experiment combining both changes in productivity and changes in education, while keeping the number of children constant. This is labeled "Prod.+Educ." in Table 6. This experiment implies results that are close to the baseline experiment, underlining the important interactions between education and productivity in the model. Similarly, the column labeled "Prod. + Fert." shows the effects of changing both Productivity and Fertility (holding Education fixed), while the column labeled "Educ. + Fert." shows the effects of changing both Education and Fertility (holding Productivity fixed).

\section{Conclusion}

Since the mid 1990s the proportion of multiple jobholders, conditional on education, decreases when productivity increases, both in the time series and in the cross-section. It 
is, however, increasing with education in the cross-section. These features remain after controlling for demographic and other economic variables. To explain these two seemingly contradictory facts, we develop an equilibrium model of the labor market where workers are heterogeneous in their preference for leisure, as well as in education. Workers adjust labor supply at the extensive margin only, deciding between various combinations of full-time and part-time jobs.

A version of the model with only two types of employment is analyzed to illustrate the key mechanisms. First, an income effect explains the negative correlation of multiple jobholding with productivity both in the time series and in the cross-section. That is, as workers become more productive they seek to increase their leisure time. This is achieved by foregoing the second job opportunity. Second, the higher prevalence of multiple jobholding among collegeeducated requires a comparative advantage effect. That is, skilled workers are relatively more productive in part-time jobs compared to unskilled workers.

The model is calibrated to U.S. data in 1994 and provides insights into what factors explain the aforementioned facts. Specifically, the model accounts for $64.1 \%$ of the 1994-to-2017 decrease in multiple jobholdings for college-educated workers, and $96.7 \%$ for high schooleducated workers. The role of productivity and education are, quantitatively, the most important. Even though the changing number of children has a non-negligible effect, it remains a second-order contributor. 


\section{REFERENCES}

Aguiar, Mark, Mark Bils, Kerwin Kofi Charles, and Erik Hurst, "Leisure luxuries and the labor supply of young men," NBER Working Paper Series, 2017, (23552).

Bar, Michael, Moshe Hazan, Oksana Leukhina, David Weiss, and Hosny Zoabi, "Why did rich families increase their fertility? Inequality and marketization of child care," Journal of Economic Growth, 2018, 23 (4), 427-463.

Chang, Yongsung, Sun-Bin Kim, Kyooho Kwon, and Richard Rogerson, "CrossSectional and Aggregate Labor Supply," ISER DP, 2019, (1063).

Goldin, Claudia and Lawrence F. Katz, The race between education and technology, Belknap Press, Cambridge, MA, 2007.

Greenwood, Jeremy, Ananth Seshadri, and Mehmet Yorukoglu, "Engines of liberation," The Review of Economic Studies, 2005, 72 (1), 109-133.

_, Nezih Guner, and Guillaume Vandenbroucke, "Family economics writ large," Journal of Economic Literature, 2017, 55 (4), 1346-1434.

Heathcote, Jonathan, Kjetil Storesletten, and Giovanni L Violante, "Consumption and labor supply with partial insurance: An analytical framework," American Economic Review, 2014, 104 (7), 2075-2126.

Heckman, James $\mathbf{J}$, "The common structure of statistical models of truncation, sample selection and limited dependent variables and a simple estimator for such models," in "Annals of Economic and Social Measurement, Volume 5, number 4," NBER, 1976, pp. $475-492$.

Hirsch, Barry T, Muhammad M Husain, and John V Winters, "Multiple job holding, local labor markets, and the business cycle," IZA Journal of Labor Economics, 2016, $5(1), 4$.

Kimmel, Jean and Karen Smith Conway, "Who moonlights and why? Evidence from the SIPP," Industrial Relations: A Journal of Economy and Society, 2001, 40 (1), 89-120.

Kopecky, Karen A, "The trend in retirement," International Economic Review, 2011, 52 (2), 287-316. 
Lalé, Etienne, "Search and multiple jobholding," 2019. Manuscript.

McGrattan, Ellen R and Richard Rogerson, "Changes in hours worked, 1950-2000," Federal Reserve Bank of Minneapolis Quarterly Review, 2004, 28 (1), 14-33.

Ngai, L Rachel and Christopher A Pissarides, "Trends in hours and economic growth," Review of Economic dynamics, 2008, 11 (2), 239-256.

Paxson, Christina $\mathbf{H}$ and Nachum Sicherman, "The dynamics of dual job holding and job mobility," Journal of labor economics, 1996, 14 (3), 357-393.

Pijoan-Mas, Josep, "Precautionary savings or working longer hours?," Review of Economic dynamics, 2006, 9 (2), 326-352.

Restuccia, Diego and Guillaume Vandenbroucke, "Explaining educational attainment across countries and over time," Review of Economic Dynamics, 2014, 17 (4), 824-841.

Rogerson, Richard, "Structural transformation and the deterioration of European labor market outcomes," Journal of political Economy, 2008, 116 (2), 235-259.

Shishko, Robert and Bernard Rostker, "The economics of multiple job holding," The American Economic Review, 1976, 66 (3), 298-308.

Vandenbroucke, Guillaume, "Trends in Hours: The US from 1900 to 1950," Journal of Economic Dynamics and Control, 2009, 33 (1), 237-249. 


\section{A Data APPEndix}

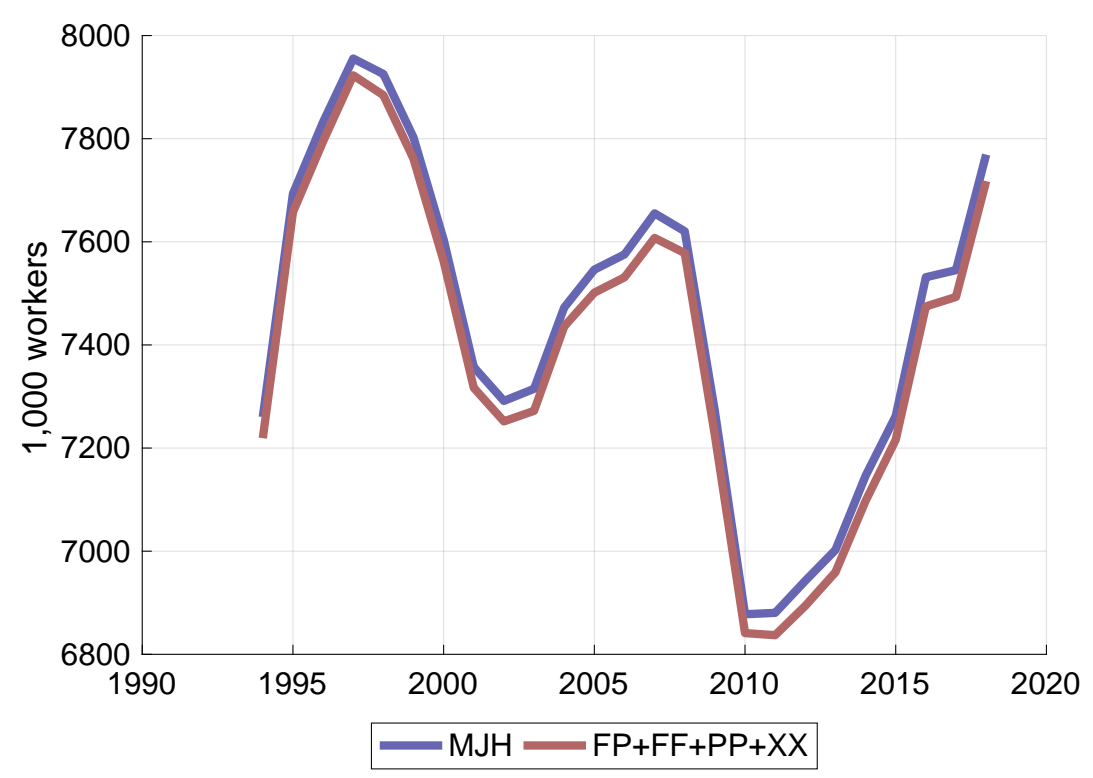

Figure A.1: Number of workers with two jobs

Note: $\mathrm{MJH}$ reports the number of multiple jobholders. The term $\mathrm{FP}+\mathrm{FF}+\mathrm{PP}+\mathrm{XX}$ refer to the sum of people holding one full-time and one part-time job (FP), two full-time jobs (FF), two part-time jobs (PP), or two jobs with variable hours on either the primary or the secondary job (XX). The difference between the two lines indicates the number of workers with more than two jobs.

Source: Bureau of labor statistics. 


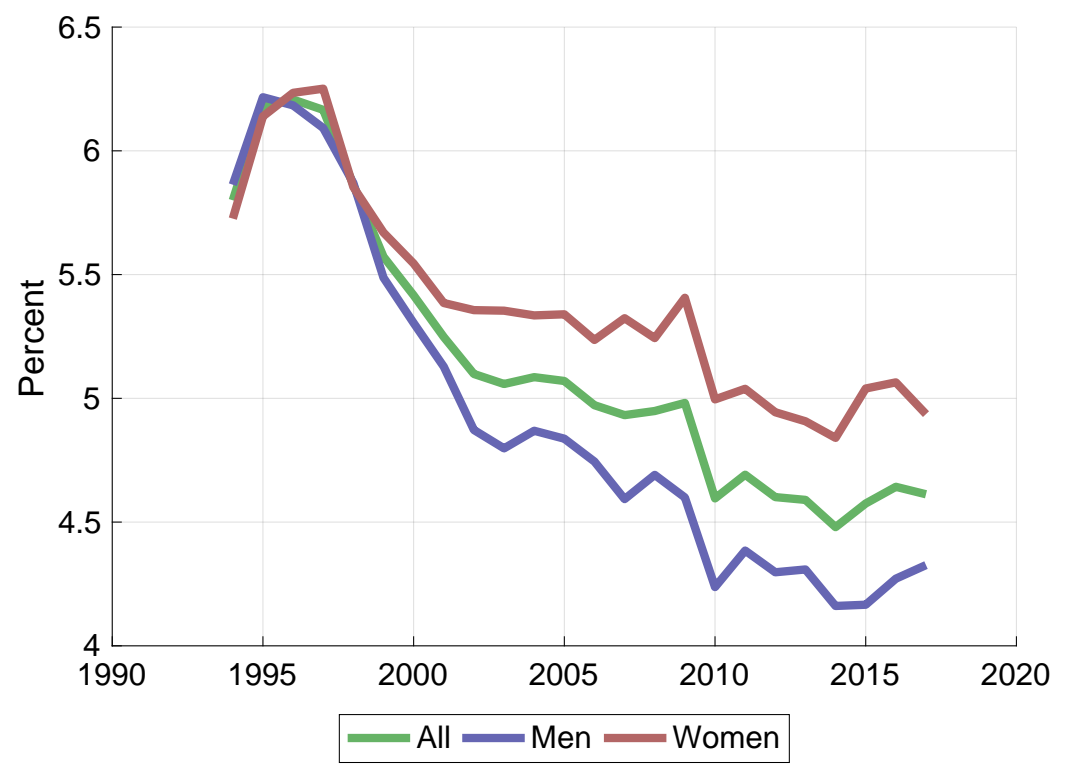

Figure A.2: Proportion of employees with multiple jobs Source: Current Population Survey. 


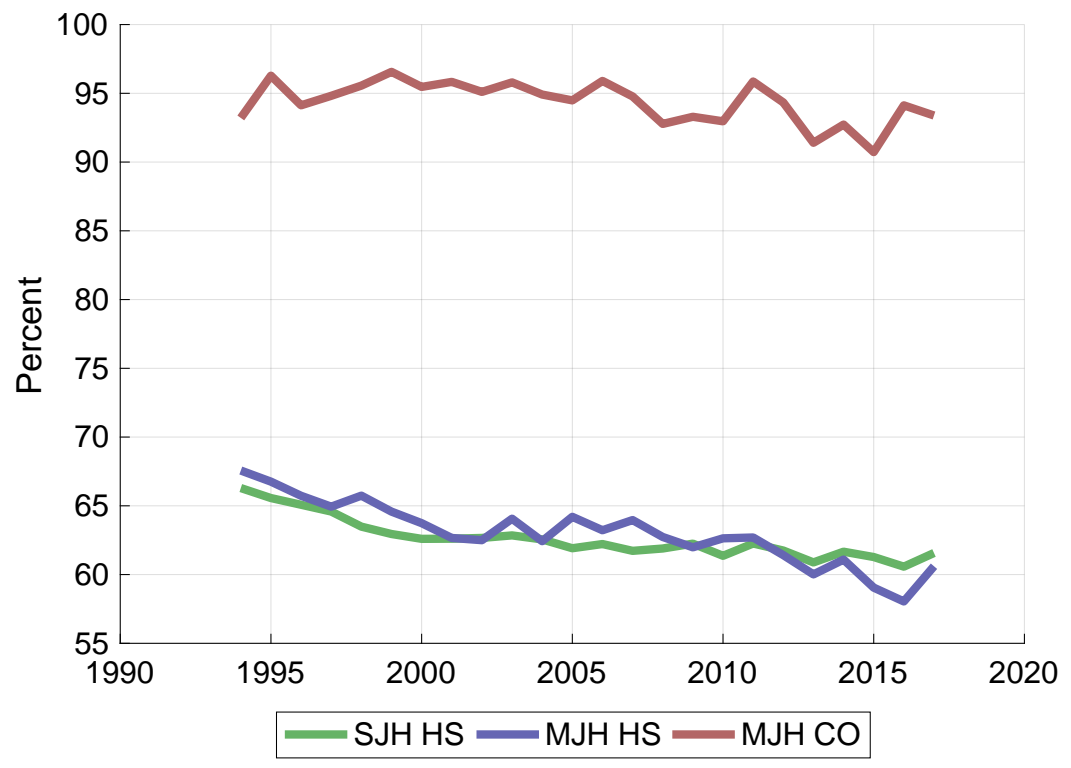

Figure A.3: Hourly earnings relative to 1-job holder, college educated

Note: "SJH" means single-job holder and "MJH" means multiple jobholders. "HS" means at most high school graduate and "CO" means some college education.

Source: Current Population Survey. 
Table 7: Probit Model Multiple Jobholding Dependent Variable

\begin{tabular}{|c|c|c|c|c|c|c|c|}
\hline Variables & $\begin{array}{c}(1) \\
\text { Model } 1 \mathrm{~F}\end{array}$ & $\begin{array}{c}(2) \\
\text { Model } 1 \mathrm{M}\end{array}$ & $\begin{array}{c}(3) \\
\text { Model 1A }\end{array}$ & $\begin{array}{c}(4) \\
\text { Model } 2 \mathrm{~F}\end{array}$ & $\begin{array}{c}(5) \\
\text { Model } 2 \mathrm{M}\end{array}$ & $\begin{array}{c}(6) \\
\text { Model } 3 \mathrm{~F}\end{array}$ & $\begin{array}{c}(7) \\
\text { Model 3M }\end{array}$ \\
\hline \multicolumn{8}{|c|}{ Education (Less than HS reference group) } \\
\hline HS & $\begin{array}{c}1.179^{* * *} \\
(0.0178)\end{array}$ & $\begin{array}{l}1.259^{* *} * \\
(0.0175)\end{array}$ & $\begin{array}{c}1.217^{* * *} * \\
(0.0131)\end{array}$ & $\begin{array}{c}1.182^{* * *} \\
(0.0177)\end{array}$ & $\begin{array}{c}1.258^{* * *} \\
(0.0174)\end{array}$ & $\begin{array}{c}1.185^{* * *} \\
(0.0187)\end{array}$ & $\begin{array}{c}1.260^{* * *} \\
(0.0174)\end{array}$ \\
\hline Some college & $\begin{array}{c}1.407^{* * *} \\
(0.0217)\end{array}$ & $\begin{array}{c}1.499^{* * *} * \\
(0.0236)\end{array}$ & $\begin{array}{c}1.453^{* * *} \\
(0.0171)\end{array}$ & $\begin{array}{l}1.411^{* * *} \\
(0.0217)\end{array}$ & $\begin{array}{c}1.498^{* * *} * \\
(0.0236)\end{array}$ & $\begin{array}{c}1.407 * * * \\
(0.0235)\end{array}$ & $\begin{array}{c}1.464^{* * *} \\
(0.0203)\end{array}$ \\
\hline College & $\begin{array}{c}1.456^{* * *} \\
(0.0272)\end{array}$ & $\begin{array}{c}1.544^{* * *} \\
(0.0277)\end{array}$ & $\begin{array}{c}1.501^{* * *} \\
(0.0210)\end{array}$ & $\begin{array}{l}1.465^{* * *} \\
(0.0273)\end{array}$ & $\begin{array}{c}1.543^{* * *} \\
(0.0277)\end{array}$ & $\begin{array}{c}1.432^{* * *} \\
(0.0303)\end{array}$ & $\begin{array}{c}1.469^{* * *} \\
(0.0253)\end{array}$ \\
\hline Advanced & $\begin{array}{c}1.646^{* * *} \\
(0.0304)\end{array}$ & $\begin{array}{c}1.755^{* * *} \\
(0.0358)\end{array}$ & $\begin{array}{c}1.703^{* * *} \\
(0.0280)\end{array}$ & $\begin{array}{c}1.668^{* * *} \\
(0.0308)\end{array}$ & $\begin{array}{c}1.755^{* * *} \\
(0.0358)\end{array}$ & $\begin{array}{c}1.598^{* * *} \\
(0.0311)\end{array}$ & $\begin{array}{c}1.609^{* * *} \\
(0.0272)\end{array}$ \\
\hline Number of children & $\begin{array}{l}0.976^{* * *} \\
(0.00227)\end{array}$ & $\begin{array}{l}1.026^{* * *} \\
(0.00294)\end{array}$ & $\begin{array}{c}1.004^{* *} \\
(0.00220)\end{array}$ & & & & \\
\hline \multicolumn{8}{|c|}{ Part-time in usual job (full-time reference group) } \\
\hline Part-time, $<20$ hrs & $\begin{array}{c}1.579^{* * *} \\
(0.0168)\end{array}$ & $\begin{array}{c}1.537^{* * *} \\
(0.0233)\end{array}$ & $\begin{array}{l}1.551^{* * *} \\
(0.0168)\end{array}$ & $\begin{array}{c}1.592^{* * *} \\
(0.0168)\end{array}$ & $\begin{array}{c}1.537^{* * *} \\
(0.0232)\end{array}$ & $\begin{array}{c}1.575^{* * *} \\
(0.0165)\end{array}$ & $\begin{array}{c}1.506^{* * *} \\
(0.0258)\end{array}$ \\
\hline Part-time, $21-34$ hrs & $\begin{array}{c}1.340^{* * *} \\
(0.0130)\end{array}$ & $\begin{array}{c}1.373^{* * *} \\
(0.0160)\end{array}$ & $\begin{array}{c}1.346^{* * *} \\
(0.0127)\end{array}$ & $\begin{array}{c}1.346^{* * *} \\
(0.0130)\end{array}$ & $\begin{array}{c}1.373^{* * *} * \\
(0.0159)\end{array}$ & $\begin{array}{c}1.334^{* * *} \\
(0.0124)\end{array}$ & $\begin{array}{c}1.364^{* * *} \\
(0.0184)\end{array}$ \\
\hline Hours vary on usual job & $\begin{array}{l}0.834^{* * *} \\
(0.00948)\end{array}$ & $\begin{array}{l}0.842^{* * *} \\
(0.0111)\end{array}$ & $\begin{array}{l}0.837^{* * *} \\
(0.00908)\end{array}$ & $\begin{array}{l}0.833^{* * *} \\
(0.00950)\end{array}$ & $\begin{array}{c}0.842^{* * *} \\
(0.0111)\end{array}$ & $\begin{array}{c}0.823^{* * *} \\
(0.0104)\end{array}$ & $\begin{array}{c}0.851^{* * *} \\
(0.0115)\end{array}$ \\
\hline \multicolumn{8}{|c|}{ Age of Children (No children under 18 reference group) } \\
\hline Child $0-2$ & & & & $\begin{array}{c}0.820 * * * \\
(0.00594)\end{array}$ & $\begin{array}{l}1.028^{* * *} \\
(0.00751)\end{array}$ & $\begin{array}{c}0.808^{* * *} \\
(0.00653)\end{array}$ & $\begin{array}{c}1.023^{* * *} \\
(0.00846)\end{array}$ \\
\hline Child 3-5 & & & & $\begin{array}{l}0.927 * * * \\
(0.00642)\end{array}$ & $\begin{array}{l}1.038^{* * *} \\
(0.00861)\end{array}$ & $\begin{array}{l}0.923^{* * *} \\
(0.00690)\end{array}$ & $\begin{array}{l}1.036^{* * *} \\
(0.00850)\end{array}$ \\
\hline Child 6-13 & & & & $\begin{array}{l}0.948^{* * *} \\
(0.00625)\end{array}$ & $\begin{array}{l}1.020^{* * *} \\
(0.00522)\end{array}$ & $\begin{array}{l}0.943^{* * *} \\
(0.00604)\end{array}$ & $\begin{array}{c}1.015^{* *} \\
(0.00594)\end{array}$ \\
\hline Child 14-17 & & & & $\begin{array}{l}1.068 * * * \\
(0.00619)\end{array}$ & $\begin{array}{l}1.062^{* * *} \\
(0.00831)\end{array}$ & $\begin{array}{l}1.060 * * * \\
(0.00574)\end{array}$ & $\begin{array}{l}1.066^{* * *} \\
(0.00882)\end{array}$ \\
\hline Female $(\mathrm{Y} / \mathrm{N})$ & & & $\begin{array}{c}0.885^{* * *} \\
(0.00625)\end{array}$ & & & & \\
\hline Real wage, 2017 \$s & $\begin{array}{c}0.999^{* * *} \\
(0.000339)\end{array}$ & $\begin{array}{c}0.997^{* * *} \\
(0.000293)\end{array}$ & $\begin{array}{c}0.998^{* * *} \\
(0.000286)\end{array}$ & $\begin{array}{c}0.999^{* * *} \\
(0.000337)\end{array}$ & $\begin{array}{c}0.997^{* * *} \\
(0.000293)\end{array}$ & $\begin{array}{c}0.999^{* * *} \\
(0.000337)\end{array}$ & $\begin{array}{c}0.998^{* * *} \\
(0.000265)\end{array}$ \\
\hline Married & $\begin{array}{l}0.829^{* * *} \\
(0.00544)\end{array}$ & $\begin{array}{c}1.038^{* * *} \\
(0.0129)\end{array}$ & $\begin{array}{l}0.894^{* * *} \\
(0.00581)\end{array}$ & $\begin{array}{l}0.835^{* * *} \\
(0.00558)\end{array}$ & $\begin{array}{c}1.040^{* * *} \\
(0.0130)\end{array}$ & $\begin{array}{l}0.834^{* * *} \\
(0.00640)\end{array}$ & $\begin{array}{c}1.052^{* * *} \\
(0.0147)\end{array}$ \\
\hline \multicolumn{8}{|c|}{ Age (Older than 60 reference group) } \\
\hline Age $20-29$ & $\begin{array}{c}1.092^{* * *} \\
(0.0162)\end{array}$ & $\begin{array}{c}1.072^{* * *} \\
(0.0138)\end{array}$ & $\begin{array}{c}1.066^{* * *} \\
(0.0120)\end{array}$ & $\begin{array}{c}1.181^{* * *} \\
(0.0174)\end{array}$ & $\begin{array}{c}1.074^{* * *} \\
(0.0134)\end{array}$ & $\begin{array}{c}1.177^{* * *} \\
(0.0192)\end{array}$ & $\begin{array}{c}1.067 * * * \\
(0.0149)\end{array}$ \\
\hline Age $30-39$ & $\begin{array}{c}1.177^{* * *} \\
(0.0133)\end{array}$ & $\begin{array}{c}1.111^{* * *} * \\
(0.0135)\end{array}$ & $\begin{array}{c}1.133^{* * *} \\
(0.0102)\end{array}$ & $\begin{array}{c}1.223^{* * *} \\
(0.0139)\end{array}$ & $\begin{array}{c}1.116^{* * *} \\
(0.0135)\end{array}$ & $\begin{array}{c}1.217^{* * *} \\
(0.0145)\end{array}$ & $\begin{array}{c}1.111^{* * *} \\
(0.0132)\end{array}$ \\
\hline Age $40-49$ & $\begin{array}{l}1.278^{* * *} \\
(0.0122)\end{array}$ & $\begin{array}{l}1.155^{* * *} \\
(0.0110)\end{array}$ & $\begin{array}{l}1.210^{* * *} \\
(0.00838)\end{array}$ & $\begin{array}{l}1.253^{* * *} \\
(0.0113)\end{array}$ & $\begin{array}{l}1.154^{* * *} \\
(0.0112)\end{array}$ & $\begin{array}{c}1.245^{* * *} \\
(0.0119)\end{array}$ & $\begin{array}{c}1.152^{* * *} \\
(0.0118)\end{array}$ \\
\hline Age $50-59$ & $\begin{array}{c}1.226^{* * *} \\
(0.0130)\end{array}$ & $\begin{array}{l}1.157^{* * *} \\
(0.0122)\end{array}$ & $\begin{array}{l}1.187^{* * *} \\
(0.00834)\end{array}$ & $\begin{array}{c}1.214^{* * *} \\
(0.0126)\end{array}$ & $\begin{array}{c}1.154^{* * *} \\
(0.0123)\end{array}$ & $\begin{array}{l}1.211^{* * *} \\
(0.0128)\end{array}$ & $\begin{array}{c}1.158^{* * *} * \\
(0.0128)\end{array}$ \\
\hline \multicolumn{8}{|c|}{ Race (White reference group) } \\
\hline Black & $\begin{array}{c}0.937^{*} * * \\
(0.0155)\end{array}$ & $\begin{array}{c}1.020 \\
(0.0189)\end{array}$ & $\begin{array}{c}0.976 \\
(0.0148)\end{array}$ & $\begin{array}{c}0.938^{* * *} \\
(0.0157)\end{array}$ & $\begin{array}{c}1.021 \\
(0.0190)\end{array}$ & $\begin{array}{c}0.935^{* * *} \\
(0.0156)\end{array}$ & $\begin{array}{c}1.003 \\
(0.0180)\end{array}$ \\
\hline Hispanic & $\begin{array}{c}0.847^{* * *} * \\
(0.0162)\end{array}$ & $\begin{array}{c}0.894^{* * *} \\
(0.0123)\end{array}$ & $\begin{array}{c}0.873^{* * *} * \\
(0.0118)\end{array}$ & $\begin{array}{c}0.847^{* * *} * \\
(0.0163)\end{array}$ & $\begin{array}{c}0.894^{* * *} * \\
(0.0124)\end{array}$ & $\begin{array}{c}0.849^{* * *} \\
(0.0168)\end{array}$ & $\begin{array}{c}0.881^{* * *} \\
(0.0125)\end{array}$ \\
\hline Other & $\begin{array}{c}0.883^{* * *} * \\
(0.0178)\end{array}$ & $\begin{array}{c}0.814^{* * *} * \\
(0.0235)\end{array}$ & $\begin{array}{c}0.848^{* * *} \\
(0.0183)\end{array}$ & $\begin{array}{c}0.886^{* * *} \\
(0.0181)\end{array}$ & $\begin{array}{c}0.813^{* * *} * \\
(0.0235)\end{array}$ & $\begin{array}{c}0.888^{* * *} \\
(0.0179)\end{array}$ & $\begin{array}{c}0.795^{* * *} * \\
(0.0243)\end{array}$ \\
\hline Constant & $\begin{array}{l}0.165^{* * *} \\
(0.00374)\end{array}$ & $\begin{array}{l}0.151^{* * *} \\
(0.00358)\end{array}$ & $\begin{array}{l}0.176^{* * *} \\
(0.00325)\end{array}$ & $\begin{array}{l}0.162^{* * *} \\
(0.00369)\end{array}$ & $\begin{array}{l}0.151^{* * *} \\
(0.00357)\end{array}$ & $\begin{array}{l}0.148^{* * *} \\
(0.00399)\end{array}$ & $\begin{array}{l}0.140^{* * * *} \\
(0.00314)\end{array}$ \\
\hline Observations & $1,018,409$ & 978,118 & $1,996,527$ & $1,018,409$ & 978,118 & 846,628 & 811,143 \\
\hline State FE & YES & YES & YES & YES & YES & YES & YES \\
\hline Year FE & YES & YES & YES & YES & YES & YES & YES \\
\hline Occupation FE & & & & & & YES & YES \\
\hline
\end{tabular}

Odds ratios presented. Robust $\mathrm{z}$ statistics in parentheses. Standard errors clustered at the state level.
. 


\section{B InCOME AND SUbSTitution EFFECTS}

In this section we consider a simple consumption-leisure problem along the intensive margin of labor supply:

$$
\max _{c, \ell}\{U(c)+V(\ell): c=w(1-\ell)\} .
$$

We show that the income effect from a change in $w$ dominates whenever $U^{\prime}(c) c$ is a decreasing function, and the substitution effect dominates whenever $U^{\prime}(c) c$ is increasing. When $U(c)=$ $\ln (c)$ the function $U^{\prime}(c) c$ is a constant (equal to 1 ) and the two effects offset each others. In the model of Section 3 labor supply adjustments do not operate along an intensive margin but along an extensive margin. The logic of income and substitution effects is the same, however.

The first-order condition for $\ell$ is $U^{\prime}(c) w=V^{\prime}(\ell)$. Combining this expression with the budget constraint implies that the optimal choice of leisure is implicitly defined by

$$
U^{\prime}(c) c=V^{\prime}(\ell)(1-\ell)
$$

The right-hand side of this equation is a decreasing function of $\ell$. When $w$ rises consumption increases. If $U^{\prime}(c) c$ is decreasing, leisure must increase, i.e. the substitution effects dominates. If $U^{\prime}(c) c$ is increasing, leisure must decrease, i.e. the substitution effects dominates. Finally, if $U^{\prime}(c) c$ is a constant (as it is with logarithmic utility), leisure is invariant to changes in $w$.

In Section 3.2 we refer to $U^{\prime}(c z) z$ being a decreasing (increasing) function of $z$ as implying that the income (substitution) effect dominates. Note that

$$
\frac{\partial}{\partial z} U^{\prime}(c z) z=U^{\prime \prime}(c z) c z+U^{\prime}(c z) \text { and } \frac{\partial}{\partial c} U^{\prime}(c) c=U^{\prime \prime}(c) c+U^{\prime}(c)
$$

therefore

$$
\operatorname{sign}\left[\frac{\partial}{\partial z} U^{\prime}(c z) z\right]=\operatorname{sign}\left[\frac{\partial}{\partial c} U^{\prime}(c) c\right] .
$$

Hence, the statement that $U^{\prime}(c z) z$ is decreasing in $z$ is equivalent to the statement $U^{\prime}(c) c$ is decreasing in $c$. 